Estudios sobre armas antiguas, arte militar y vida cultural en oriente y occidente XXXII (2012), pp. 185-210

ISSN : 0436-029X

doi: 10.3989/gladius.2012.0009

\title{
UNA NUEVA PIEZA DE ARTILLERIA DE GALERAS DEL SIGLO XVI: EL ESMERIL BASTARDO «MATACAPITANES»*
}

\author{
A NEW TYPE OF ORDNANCE FOR GALLEYS IN THE 16TH C. AD: \\ THE «CAPTAIN-KILLER» ESMERIL BASTARDO
}

POR

\author{
Pedro Fondevila Silva** y Juan José Sánchez Baena***
}

\section{RESUMEN - ABSTRACT}

Trabajo de investigación que presenta y analiza una pieza desconocida de artillería naval de la segunda mitad del siglo XVI, localizada sin inventariar en una de las salas del Archivo-Museo «Don Álvaro de Bazán» del Palacio de El Viso del Marqués en Ciudad Real (España). Se trata de un esmeril bastardo que hemos bautizado como «matacapitanes», por ser un modelo diseñado para optimizar su empleo contra los oficiales enemigos protegidos con armaduras a prueba de balas de arcabuz. Además, se realiza una aproximación al estudio de la tipología y clasificación de la artillería naval del siglo XVI a través de los documentos, tanto manuscritos como impresos, de esa época.

This work is aimed at the analysis of an unknown piece of maritime artillery dated at the second half of the XVIth century. This piece, out of any inventory record, was located within one of the Archive-Museum chambers in the Don Álvaro Bazán Palace at El Viso del Marqués, Ciudad Real province, central Spain. The specimen is a bastard esmeril here so-called «matacapitanes» («killer of captains») because it seems precisely designed to be used against the bullet-proof armour of enemy officers. By means of manuscripts and impressed documents, an approach and discussion on the typology and classification of the XVIth century's maritime artillery is also presented.

\section{Palabras Clave - Keywords}

Artillería; Cañón; Galera; Esmeril; Guerra; España; Museo; Siglo XVI; Marqués de Santa Cruz; Álvaro de Bazán.

Artillery; Cannon; Galley; Esmeril; Emery; War; Spain; Museum; XVI century; Marquis de Santa Cruz; Alvaro de Bazan.

\section{INTRODUCCIÓN}

El propósito de este trabajo es dar a conocer, por un lado, una pieza de artillería utilizada en las galeras españolas del siglo XVI, que hemos descubierto e identificado recientemente, de

\footnotetext{
* Este trabajo es uno de los resultados del Proyecto I+D+i del Ministerio de Ciencia e Innovación, con referencia HUM-2007-61093/HIST y del Proyecto Argos II, 11936/PHCS/09, financiado por la Fundación Séneca, dirigidos por la Dra. Celia Chaín Navarro.

** Cátedra de Historia Naval (Armada - Universidad de Murcia). Campus de Excelencia «Mare Nostrum». Correo electrónico: cazalamesana@gmail.com

*** Profesor titular de Historia de la Universidad de Murcia y director de la Cátedra de Historia Naval. Correo electrónico: baena@um.es
} 
un tipo hasta ahora desconocido y que creemos única en los museos navales españoles; y, por otra parte, situar dicha pieza en la artillería de las galeras de la época.

La pieza de artillería que presentamos, describimos y analizamos, se encontraba localizada en el rincón de una de las salas de exposición (sala Argos) en la parte oeste de la planta superior del Palacio Renacentista de Álvaro de Bazán, en El Viso del Marqués (Ciudad Real), sin ningún tipo de identificación ni información al público. Esta pieza debió aparecer en las obras de restauración y adaptación de los camaranchones del palacio, al comienzo de los años 50 del pasado siglo. Es posible que pasara inadvertida, por desconocimiento temático o por olvido, cuando se habilitaron las salas y las piezas para este fin museístico, ya que todos los objetos que componen la colección estable de este palacio gestionado por la Armada e integrado en la red de museos periféricos del Museo Naval de Madrid, sí que están descritos y referenciados.

La importancia de la pieza, que consideramos de gran interés, es doble: por un lado podría estar asociada a una de las más señeras figuras navales españolas de ese siglo (Álvaro de Bazán, primer Marqués de Santa Cruz), y a la batalla naval más importante de esa época (Lepanto); por otra parte la pieza, en unas condiciones de conservación extraordinarias, no ha tenido ninguna intervención desde que se guardó en el siglo XVI, llegando a nosotros con todos sus elementos originales, lo cual nos ha permitido averiguar aspectos inéditos, que nos obligan a replantear algunas de las interpretaciones e intervenciones anteriores realizadas en piezas de la época rescatadas del mar.

De esta manera, los pasos que pretendemos seguir para el estudio de la pieza consistirán, básicamente, en una descripción y análisis de ésta, de forma que, con los nuevos datos obtenidos, se pueda plantear una nueva interpretación de otras piezas museísticas y corregir aquellas intervenciones anteriores que aparezcan como erróneas.

Debido a la falta de trabajos específicos sobre artillería naval hemos realizado una aproximación al estudio y análisis de la tipología de la artillería naval del siglo XVI a través de los documentos de archivo y las obras impresas de esa época. Al final de este trabajo hemos añadido en apéndice un documento de 1590, que creemos que puede ser básico para clarificar esta cuestión.

\section{CONSIDERACIONES PREVIAS Y ESTADO DE LA CUESTIÓN}

Una de las mayores dificultades para aproximarse a la artillería naval española del siglo XVI radica en la falta de un criterio uniforme para catalogar las piezas. Los libros españoles sobre artillería editados en esa época trasladan con relativa frecuencia datos farragosos e inseguros, debido a la falta de normalización de las piezas y al hecho de que cada fundidor aplicaba su sistema ocultándolo a sus competidores. Por otro lado, en esas publicaciones no hay, prácticamente, ninguna referencia a la artillería naval y menos aún a la de las galeras. Sin embargo, como se irá justificando a lo largo de este trabajo, las piezas de estas últimas se fabricaban, probablemente por indicación de los mandos de las galeras que las encargaban, teniendo en cuenta las especiales características de estas embarcaciones. Estas dificultades explican, a nuestro juicio, la falta de publicaciones españolas de referencia sobre este tema.

Para intentar una catalogación de las piezas, vistos los inconvenientes apuntados, consideramos que la mejor solución es un estudio de las características técnicas de estas, empleando la información de las relaciones de artillería y contrastándola con un análisis crítico de los datos de los libros de artillería de esa época. La otra opción, cuando existe esa posibilidad, es compararlas con materiales análogos.

Posiblemente el primer problema radique en la diferencia que existe entre el concepto actual de artillería y el que existía durante la Edad Moderna. Según Vicente Maroto «el arte 
militar era el resultado de un conjunto de técnicas diversas que entonces se agrupaban bajo la denominación de «artillería», que tenía un sentido más amplio que el actual» ${ }^{1}$. Esta idea, que consideramos un acertado juicio del concepto de artillería en los siglos XVI y XVII, es fundamental para aproximarnos y enfocar las obras sobre ese tema escritas en los siglos citados.

Pasemos ahora a analizar los trabajos de algunos de los autores de obras sobre la artillería, porque sobre ellos se ha fundamentado, al menos en lo que a la artillería naval se refiere, la clasificación y catalogación de las bocas de fuego navales. Así Fernández Duro, cuyo trabajo ha sido el referente para estudios posteriores, nos dice:

El primero de nuestros escritores artilleros [(46) D. Diego de Alava. El perfecto capitan instruido en la disciplina militar y nueva ciencia de la artillería, Madrid, 1590] explicó lo que significa una parte de esos nombres extraños.

El mosquete, dice, tira dos onzas de bala de plomo.

El esmeril, de 6 a 12 onzas.

El falconete, de 3 a 4 libras de bala (... $)^{2}$.

Analizando el texto anterior hay que corregir la frase «El primero de nuestros escritores artilleros», añadiéndole el adjetivo publicado, pues escritores anteriores hay, como el Tratado de Artillería del Capitan Gaspar Gonzalez de San Millan, Artillero Mayor de la Casa de Contratacion de las Indias, de la Ciudad de Sevilla ${ }^{3}$, cuyo trabajo, redactado hacia mediados del siglo XVI, tiene la ventaja de tratar de artillería naval y estar escrito por un profesional. ¿Y porqué enfatizamos la última palabra? Porque Diego de Álava era jurista, aunque hijo del Capitán General de la Artillería Frances de Álava, que anteriormente había dirigido la fundición de Málaga. Ello explicaría la obra (y en concreto el Libro tercero, titulado En que se trata todo lo necesario a las fundiciones de artillería, y municiones della ${ }^{4}$, que es un completo tratado de fundición), y que ésta fuese publicada, pues, aparte del dinero que había que tener para pagar la edición, era necesario el permiso real.

En ese orden de ideas, veamos el juicio que le merece la obra a un coetáneo. Así en el memorial que dirige al Rey Alonso de Salamanca, maestro mayor de artillería, solicitando el permiso para editar una obra suya, dice lo siguiente al justificar su trabajo:

No hay en la lengua castellana su semejante porque, si bien en los mas libros militares se trata algo de esto, y mas en particular por uno del perfecto capitan que de presente ha salido, es cosa cierta que no hay en ellos razon de maestro que haya servido artilleria, por donde se conocen que lo que declaran ha sido sacado de papeles mal entendidos y de un libro de lengua toscana ${ }^{5}$ fundado en geometría y matematica y proporcion que es una ciencia mal entendida de los mas artilleros, cuyo oficio consiste mas en razon de experiencias y en saber perfectamente obrarlas $^{6}$.

Aunque pudiera parecer que este juicio es fruto de la envidia, creemos que refleja la realidad, y que Diego de Álava dispuso de abundante documentación, «lo que declaran ha sido sacado de papeles mal entendidos», pero su desconocimiento del tema le hizo cometer erro-

\footnotetext{
1 Vicente Maroto, M. I. (2002-2003): «Las escuelas de artillería en los siglos XVI y XVII». Quaderns d'història de l'enginyeria. Volum V. Pág. 1. Disponible en http://upcommons.upc.edu/revistes/bitstream/2099/734/1/escuelas_artilleria.pdf.

2 Fernández Duro, C. (1996): Disquisiciones Náuticas. Volumen I. Madrid, Ministerio de Defensa. Págs. 43-44.

3 Ibidem. Volumen VI. Págs. 481-500.

4 Alava y Beamont, D. de. (1590): El perfecto capitán instruido a la disciplina militar y nueva ciencia de la Artilleria. Madrid, Pedro Madrigal. Pág. 152.

5 Se refiere a la obra de Tartaglia, N. (1551): Tratrato di balistica in cinque libri. Venezia.

6 Vicente Maroto, M. I. Op. cit. Pág. 6.
} 
res como este: «Los cañones que llaman sutiles, y todos los demas, tienen de largo deziocho diámetros de su mesma boca, y los que excedieran desta longitud, se llamaran cañones bastardos» ${ }^{7}$. Si hay algo en que todos los autores estén de acuerdo es en calificar las piezas de bastardas, cuando la relación del largo del ánima con respecto al diámetro de la boca es menor del que define su género. Por tanto, el error indicado no es creíble en una persona experta, pero si explicable en un individuo que está componiendo un trabajo, sobre un tema que no domina, exclusivamente a base de documentación.

Tomemos en este momento la famosa obra de Diego Ufano ${ }^{8}$, que aparece citada varias veces en el excelente trabajo de Arántegui ${ }^{9}$. Veamos la opinión que le merece: «No es fácil deducir cual de los dos autores expone la verdad, pues aunque Ufano escribía en la época más próxima al hecho, ha fantaseado algo en lo relativo a nombres y clasificación de piezas, involucrando las de todos los dominios españoles» ${ }^{10}$.

De esa cita se desprende que Ufano incorporó a su trabajo una serie de datos que le llegaron, de otros dominios españoles distintos de Flandes, a través de documentos, creando una copiosa selva de datos y tablas que pudieron servir para acrecentar su prestigio, pero que crearon una enorme confusión, como atinadamente observa Arántegui, en lo relativo a nombres y clasificación de piezas.

Este aspecto del nombre y clasificación de las piezas es el meollo de la cuestión, pues de lo que se trata es, ante una nueva pieza, el poder catalogarla y darle el nombre que se utilizaba en la época. No es tarea fácil, visto el caos de tipos y nombres de piezas de ese siglo. Véanse algunas opiniones:

(...) pero como cada fundidor daba las longitudes y espesores a su capricho, resultaba que bajo una misma denominación existían piezas de diferentes pesos, y lo que es peor, de distinto calibre $^{11}$;

Del largo de las pieças ay gran controversia ${ }^{12}$,

La diversidad y multitud de piezas creció hasta lo increíble, (...) Inundáronse los ejércitos y plazas de dragones, áspides, basiliscos, serpentines, serenas, pelícanos, sacres, falcones, falconetes, girifaltes, ribadoquines, esmeriles, pasadores, culebrinas y sus derivados. A éstos se agregaron otras bocas de fuego de mayor calibre, y con nombres más hinchados; los despertadores, siflantes, trabucantes, rifadores, rebufos, crepantes, verracos. Molesto sería referirlos todos ${ }^{13}$.

Incluso opiniones actuales que tratan de forma sucinta este asunto, ponen de manifiesto la complejidad arriba apuntada:

Basilisks, serpents, minions, robinets, falcons, bastards, sirens, bases, slings: the multiple, evocative names, of Renaissance artillery defy order, or even understanding - contemporaries railed against the needles proliferation of calibres, which could only complicate logistics and

7 Alava y Bamont, D. de. Op. cit. Pág. 161.

8 Ufano, D. (1613): Tratado de la Artilleria y uso della Platicado por el capitan diego ufano en las guerras de Flandes. Bruselas, Juan Monarte.

9 Arántegui y Sanz, J. (1891): Apuntes históricos sobre la Artillería Española. Madrid, Imprenta del Cuerpo de Artillería.

10 Ibidem. Pág. 339.

11 Ibidem. Pág. 332.

12 Alava y Beamont, D. de. Op. cit. Pág. 154 v.

13 Fernández Duro, C. Op. cit. Volumen I. Págs. 42-43. 
stymie wartime efficiency. Even after cannon came to be generally standardized by named category and weight of shot, the categories were not fully consistent between different services (say, Spanish and English) and measures differed between jurisdiction (as between Venetian and Milanese «pounds» and «feet») $)^{14}$.

Establecido lo anterior, abordemos otro aspecto de la cuestión como es el que los libros de artillería de la época considerada contemplan, prácticamente de forma exclusiva, únicamente la artillería terrestre. Solamente algún autor se refiere de forma breve a las piezas navales: «Este modo de cargar las pieças con cartuchos fue inventado, y debe usarse en bajeles» ${ }^{15}$. Esta práctica debió comenzarse en la primera mitad del siglo XVI, pues en una lámina ${ }^{16}$ aparecen galeras imperiales con el artillero en la tamboreta, cargando la pólvora en el cañón de crujía con cuchara, y aunque la fecha del dibujo es de 1562, el modelo de galera representado es de comienzos de ese siglo.

Entre algunas obras de construcción naval ${ }^{17}$ y de navegación ${ }^{18}$ se encuentran capítulos y apartados sobre artillería naval que, si bien están dedicados a la organización y al combate, no dejan de presentar datos interesantes sobre los modelos de bocas de fuego. También varios manuscritos, entre ellos el de Andrés de Espinosa, recogido por Fernández Duro ${ }^{19}$, que junto al de Gaspar González de San Millán ${ }^{20}$, proporcionan interesantes datos acerca de la artillería naval y su diferencia con la terrestre ("fuera de estas piezas que se usan en la mar, son muchas las diferencias de las piezas que se traen en campaña y hay en los presidios ${ }^{21}{ }^{2}$ ).

Sin embargo, ninguno de los libros y manuscritos citados hacen, prácticamente, mención a la artillería de las galeras, objeto de este trabajo. Tenemos que apoyarnos en algunas de las relaciones de artillería de galeras, extremo este del que trataremos cuando realicemos la descripción y catalogación de la pieza en cuestión.

Falta por tratar un último aspecto, el dar el viento a la bala: «el dar el viento á la bala es un intervalo entre la bala y el hueco de la pieza, que no entra muy justa y apretada; siendo mal redonda pone en peligro de reventarse la pieza; ni tampoco debe entrar la bala muy floja, porque sería de poco efecto, porque no tomará toda la fuerza de la pólvora y se iría en el viento demasiado, y así se ha de ajustar á que tenga sólo el viento necesario» ${ }^{22}$.

Este punto es esencial pues, a no ser que encontremos la pieza cargada y con la bala en muy buen estado de conservación, que permita obtener su peso y diámetro con seguridad, para determinar el calibre de su bala habrá que medir el diámetro del ánima y a este valor quitarle el viento para obtener el diámetro de la bala, el cual hay que transformar en peso en libras u onzas, según el caso, considerando el material del proyectil, hierro, plomo o piedra, que lanzaba la pieza, para determinar su calibre.

Apuntar aquí todas las distintas reglas que se proponen en los libros y manuscritos citados no tendría objeto, por aportar cada autor reglas diferentes, que si bien próximas, proporcionarían, sobre todo en los calibres pequeños, que es el caso de este trabajo, resultados distintos e

14 Arnold, T. (2001): The Renaissance at War. London, Cassell and Co.

15 Firrufino, J.C. (1626): Platica manual y breve compendio de artilleria. Madrid, viuda de Alonso Martín. Pág. 28 v.

16 Raben, G; Fayerabend, S. y Huter, S. (1566). Thurnier Buch, Warhaffiter ritlerlicher Thate. Frankfurt ann Main, in frenen felt. Pág. LXVIII.

17 García de Palacio, D. de. (1587): Instrucion Nauthica, para el buen uso, y regimiento de las Naos, su traça, y govierno conforme a la altura de Mexico. Mexico, Pedro Ocharte.

18 Escalante de Mendoza, J. de. (1985): Itinerario de Navegación. Edición facsímil. Madrid, Museo Naval de Madrid.

19 Fernández Duro, C. Op. cit. Volumen VI. Págs. 440-456.

20 Ibidem. Págs. 480-500.

21 Ibidem. Pág. 450.

22 Ibidem. Pág. 491. 
inseguros. Como ya hemos apuntado, emplearemos los valores del viento que se utilizaban en las galeras españolas en la época de datación de la pieza objeto de estudio, sacadas de algunas relaciones de artillería de galeras que aquí se citan.

Para acabar este apartado traemos a colación el esmeril de una galera de 8 onzas de pelota existente en el Museo Naval de Madrid con el no 1407 de catálogo (figs. 1, 2, 3 y 4). Conocemos documentalmente el nombre de la galera en que estaba montado, la fecha y el lugar exacto en que se perdió, el expediente de hallazgo de la pieza (figs. 3 y 4), en el sitio preciso que indica el anterior documento, pero, por razones de seguridad del Patrimonio Histórico Español, dado que el pecio no ha sido excavado, solamente indicaremos que la fecha en la que se hundió la galera, que fue en el año 1539.

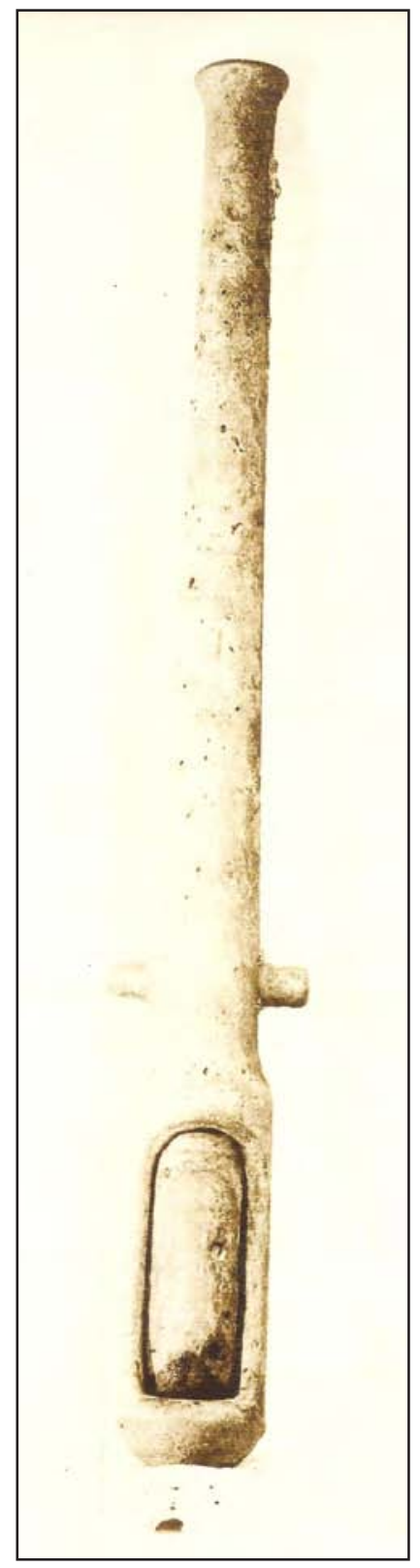

Figura 1. Fotografía del esmeril de galera, visto por la parte superior, que figura en el expediente de hallazgo, con el másculo dentro de la cámara abierta. Museo Naval de Madrid, ${ }^{\circ} 1407$.

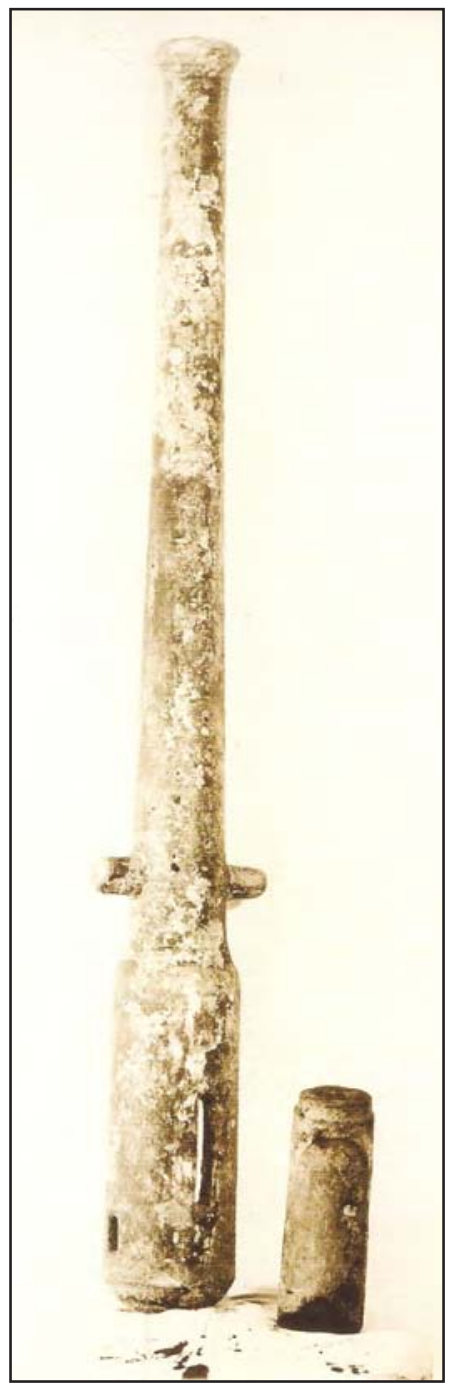

Figura 2. Fotografía del esmeril de galera que figura en el expediente de hallazgo, visto por la parte inferior y con el másculo retirado. Se aprecia, a la izquierda, el orificio para introducir la cuña de hierro (desaparecida por corrosión) y, en el centro, la ranura que servía para golpear desde abajo, cuando fuese necesario, el másculo para desencajarlo. Museo Naval de Madrid, $n^{0} 1407$. 


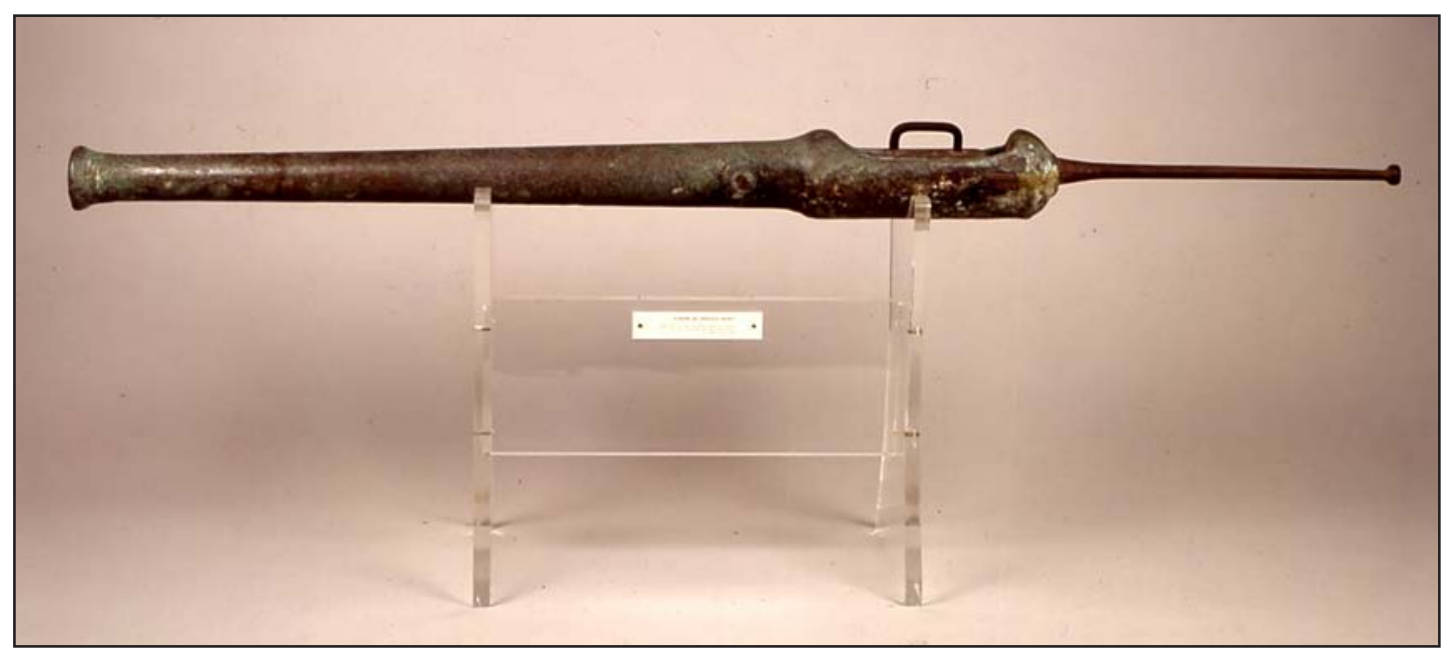

Figura 3. Vista lateral de la misma pieza en el Museo Naval de Madrid, registrada, como verso, con el $n^{\circ}$ 1407. Aparte de la errónea clasificación, son visibles las equivocadas reconstrucciones del asa del másculo en hierro (tendría que ser de bronce) y de la rabiza en hierro, dado que esta era de madera y desmontable.

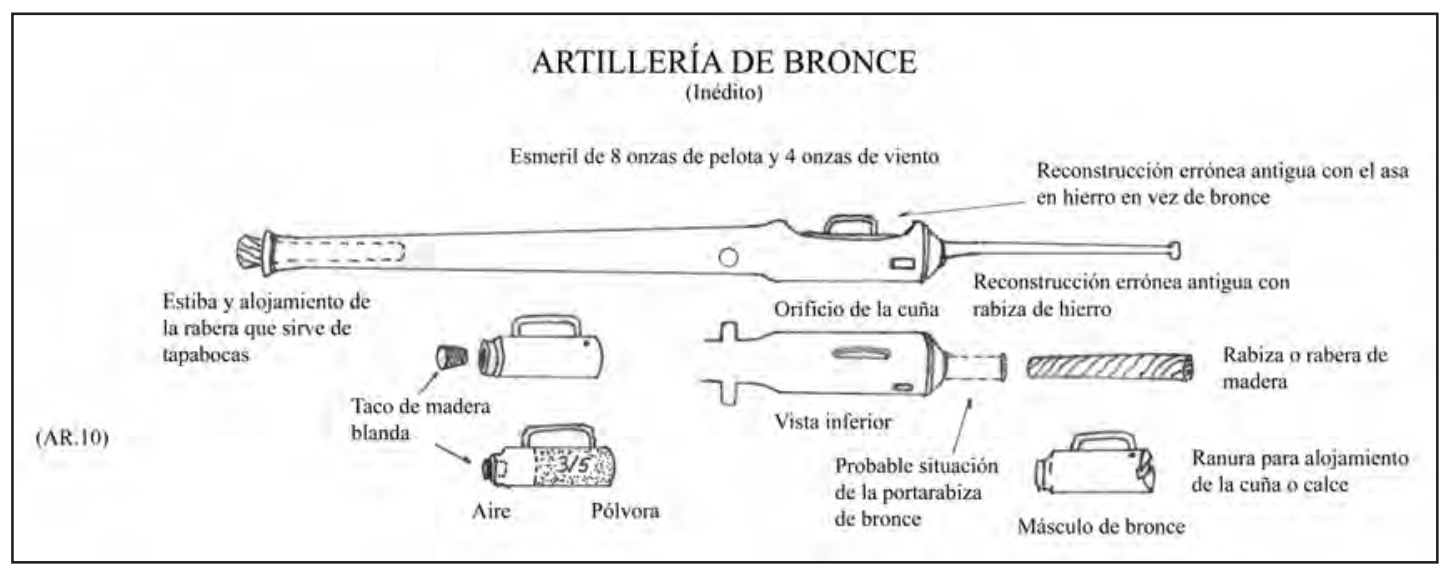

Figura 4. Dibujo de Pedro Fondevila con la reconstrucción correcta del esmeril de galera de 1539.

La pieza está erróneamente clasificada como verso y ha sufrido equivocadas intervenciones que se detallan en la figura 4, la cual forma parte de un trabajo en curso de recatalogación y estudio de varias piezas de artillería del citado museo. La pieza en cuestión, que muestra restos de la portarrabiza en buena parte destrozados por la colocación posterior de una rabiza de hierro, es un esmeril de cámara abierta, cuyo másculo, servidor, recámara o alcuza se encontró cargado y con el taco de madera en la boca. Pertenece a un estadio anterior al del esmeril «matacapitanes», el cual se optimizó para su uso haciéndolo de cámara cerrada y acortando la longitud, calibres, del ánima.

Otros esmeriles que presentan soluciones semejantes para hacer que la rabiza sea desmontable, son los correspondientes a los números de catálogo 1406, 1408 y 6361 del Museo Naval de Madrid. Pero están todavía pendientes de estudio. 


\section{LAS PIEZAS DE ARTILLERÍA DE LAS GALERAS}

Para adentrarnos en la compleja tipología de la artillería de la época, conviene indicar que las piezas estaban divididas en tres géneros: el primero lo formaban las culebrinas; el segundo los cañones, y el tercero los pedreros. A su vez, cada género tenía un abundante número de modelos que se iban mudando según el capricho del fundidor o el resultado que hubieren dado («Antiguamente los fundidores ponían a las piezas que habían fundido los nombres a su voluntad. Hoy en día se divide toda esa variedad en tres géneros solamente. Primero, segundo y tercero. En el primero se contienen toda suerte de artillería larga o aculebrinada. En el segundo toda suerte de cañones. En el tercero todo género de piezas que se dicen pedreros» ${ }^{23}$ ).

Tratando ahora de la artillería de las galeras españolas, estas iban armadas con dos tipos diferentes de piezas: un conjunto de bocas de fuego, cuyo propósito principal era ofender el buco, árboles y aparejos de la embarcación enemiga, que apellidaremos «antibuque»; y otro grupo de piezas encaminadas a batir a la dotación enemiga, las cuales llamaremos «antidotación».

Las armas antibuque estaban situadas en la proa de la galera, en un espacio llamado la corulla, que en la primera mitad del siglo XVI iba descubierta, con lo cual se podían colocar piezas de horquilla sobre los maimones y maímonetes, tal como podemos contemplar en la figura $5^{24}$, que represente una galera capitana papalina. En la segunda mitad la corulla se cubre con la arrumbada, la cual se apoya sobre los maimones, ahora llamados bitas, con lo que la artillería de horquilla pasa, bien a la arrumbada, bien al corredor, manteniéndose en la corulla la artillería antibuque.

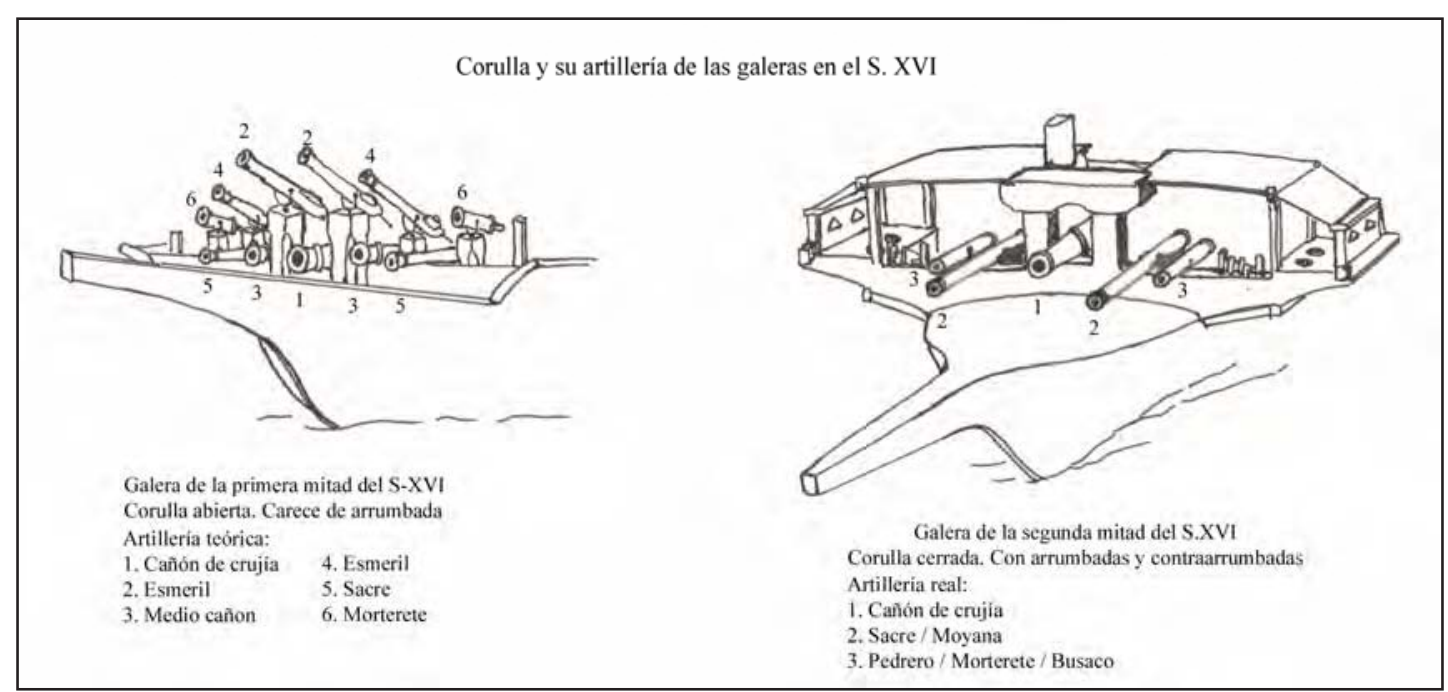

Figura 5. Dibujos de la corullla y su artillería en las galeras del siglo XVI. Fuente: Elaboración propia a partir de un dibujo de Pieter Brueghel. Museo Naval Madrid. Sign. 3944.

23 Serneira de Aguilar, M. Ms. «Advertencias de Navegantes». Primera mitad del S. XVII. Biblioteca Nacional de Portugal. Cod - 13390, fol. $18 \mathrm{v}$.

24 Dibujo basado en un grabado de Frans Huys según un dibujo de Pieter Brueghel. Tres galeras y un galeón. Museo Naval de Madrid. Sign. 3944. 
La pieza principal era el cañón de crujía, situado en la crujía, de ahí su nombre, entre los dos maimones o bitas. Era una pieza de tipo cañón de grueso calibre, normalmente entre «30 a 20 libras de peso de bala de hierro». A ambas bandas se colocaban otras dos piezas del tipo culebrina: sacres, falconetes o moyanas. Éstas eran de las llamadas de caza, es decir, piezas de menor calibre pero de mayor alcance, que se empleaban en la persecución o caza de una embarcación, para tratar de alcanzar su aparejo o desorganizar su boga, y, así, poder abordarla.

Las armas «antidotación» estaban formadas por las piezas menores del tipo culebrina, normalmente por esmeriles y por diferentes tipos de pedreros: cañones pedreros, busacos y morteretes. Los esmeriles servían para tirar contra blancos determinados. Los cañones pedreros y busacos, lanzaban balas o bolardos de piedra caliza, los cuales, al chocar con un cuerpo sólido, se disgregaban en numerosas esquirlas que actuaban a manera de metralla contra la dotación. Los morteretes, que también podían lanzar balas de piedra, se utilizaban para disparar lanternas, que eran unos cilindros huecos de madera blanda, rellenas de perdigones, dados de hierro o lascas de pedernal, que funcionaban como botes de metralla.

Veamos ahora una relación del armamento de las galeras en la primera mitad del siglo XVI, cuando la corulla estaba abierta. Esta en una relación «teórica», es decir, que es lo que se pide desde la atarazana para armar las galeras que están construyendo. Otra cosa es lo que les montaran.

Año de 1539. Memorial de las Municiones que son menester para las Veinte galeras que estan en las Atarazanas de la presente Ciudad de Barzelona. Artilleria: Veinte cañones de Cusia de proa, uno por cada galera. Quarenta medios cañones arrimados a los maymones grandes de proa, dos por cada galera. Quarenta sacres arrimados entre los maymonetes dos por cada galera. Ochenta esmeriles con sus Serbidores los cuarenta para los maymones grandes de proa, y los otros cuarenta para los maymonetes, que es a saber quatro de los dichos esmeriles con sus serbidores para cada galera, los dos de ellos para los maymones grandes de proa y los otros dos para los maymonetes. Veinte medios Cañones a la parte del Esquife es a saber un medio Cañon cada galera. Otros veinte medios cañones a la parte del fogon es a saber medio cañon por cada galera. Ciento y sesenta Smeriles para los corbatones y maymonetes de popa con sus Servidores es a saber ocho esmeriles por cada galera. Ochenta morteretes de bronzo para tirar perdigones con lanternas es a saber quatro morteretes para cada galera dos para proa y los dos para popa ${ }^{25}$.

En realidad, el armamento montado era, en muchas ocasiones, diferente a lo solicitado. Aunque la casuística es variada, podemos mencionar las siguientes prácticas: al darse de baja una galera, la nueva que le sustituía «heredaba» la artillería; cuando se apresaba una embarcación enemiga, su artillería se repartía entre las galeras apresadoras; los capitanes generales de las escuadras de galeras solían encargar o comprar piezas en otros reinos o dominios de España, etc. Para hacernos una idea, transcribiremos más adelante una relación de las piezas de artillería que montaban, las 19 galeras de la Escuadra de España, en la segunda mitad del siglo XVI. Este documento, que consideramos de gran importancia, nos proporciona el tipo, peso, calibre y viento de las piezas, aspecto este fundamental para la catalogación de los objetos museísticos, pero, además, nos permite una completa visión de las prácticas al uso en cuestión de armamentos, pues, a título de ejemplo, en el texto aparece, confirmando lo anteriormente formulado, que las bocas de fuego de esas galeras eran originarias de diez países y reinos diferentes.

Este uso era común en todas las escuadras de galeras, cristianas y musulmanas, como veremos en el interesante texto que sigue; y como las piezas de artillería de bronce son uno

25 Museo Naval de Madrid. Colección Sanz de Barutell. Artículo 4, nº 122. 
de los elementos más duraderos de un pecio y muy utilizado para identificarlo, no está nunca de más señalar el extremo cuidado con el que hay que actuar en la arqueología subacuática, al tratar de determinar la nacionalidad de la embarcación por medio de la artillería encontrada en el pecio, ya que el apresamiento y confiscación de estas era común, lo que podía suponer que en una galera española se encontraran, por ejemplo, armas turcas o viceversa :

certificamos que por orden nuestra entrego las dichas tres galeras turquescas que tomo, a los oficiales de esta Santa Liga, con veinte y y una piezas de artilleria de bronce, es a saber: tres cañones de crujia, los dos con las armas de Sicilia y el uno con las del principe Andrea Doria, que a lo que se entendio fueron perdidas en las jornadas de la Preveza y los Gelves, y las nueve sacres, todas con las armas de la sacra religión de San Juan, y las once restantes, medios sacres y falconetes, parte con las armas del Serenisimo Cesar emperador Maximiliano, y parte con unos fuegos y lunas... y cuatro campanas de metal de diferentes tamaños que eran de Corfu y otras tierras donde los dichos turcos saquearon ${ }^{26}$.

Abundando en la importancia de la pieza que aquí analizamos, hay que decir que la escasez de piezas de bronce de artillería naval fue consecuencia de la reutilización de los cañones estropeados, desfogonados ${ }^{27}$, o anticuados, que se fundían para hacer nuevas piezas.

Fecha 6 de noviembre de 1538. Que los proveedores le han escrito que se manden quebrar los cañones Aguilas y los pelicanos y la Culebrina de Alemania y ocho medias culebrinas que son XXVIII piezas lo que a su parecer no se deberia hacer, sin vuscar metal para las que se han de fundir de nuevo porque estas piezas son buenas para la mar y aunque se tenga por inconveniente ser de diferentes pelotas aprovecharan para lo que tiene dicho y para poner en fortaleza porque estan bien aderezadas y encabalgadas y las que se han de hazer de nuevo podria ser que no se adereszasen a tiempo que pudiesen servir esta Armada ${ }^{28}$.

Relacion de lo que pesaron las nueve Moyanas de Bronze que últimamente desecharon las Galeras de Spaña y se entregaron a henrique bauet Asentista de la fundicion de la Artilleria de esta ciudad por estar inútiles y para que fuesen a fundir y fabricar otras nueve Moyanas ${ }^{29}$.

Esta práctica venía motivada por el alto precio de los cañones de bronce en comparación con los del mismo tamaño realizados en hierro colado. La proporción, variable según la época, estaba en un valor de 8 a 10 veces más cara la pieza de bronce que la de hierro. Este valor tan alto del bronce, hacía que la mayoría de las piezas fuesen pesadas y su resultado marcado en la fundición, y que éste figurase en los inventarios y listas de la artillería.

Fecha 8 de Mayo de 1587, Napoles. Cargo de armas y artilleria y otras cosas pertenecientes a ella: Un cañon de bronze de 12 palmos largo, de 50 libras de bala, con armas reales y del Marques de Mondejar con letrero Opus Christoforo de jordano, de Napoles A.D. 1579, de peso señalado a la culata, quintales 34 , rotulos 36 , con su caxa y ruedas husadas herradas ${ }^{30}$.

A pesar de lo dicho, en las galeras se utilizó siempre, con la excepción de los primeros años del siglo la artillería de bronce («Noticia del armamento hecho para el viaje del rey $D$. Fernando a Nápoles en 1506 (...). Extracto del Inventario de la Galera Real (...) Ytem una

26 Cajal Valero, A. (2006): «Una presencia vasca en Lepanto: Domingo de Zavala». Itsas Memoria. Revista de Estudios Marítimos del País Vasco, 5: 139-140.

27 Para todas las voces en cursiva que no estén dentro de los signos $<>$, utilizados aquí como paréntesis, V. Fondevila Silva, P. (2011): Diccionario Español de la Lengua Franca Marinera Mediterránea. Murcia, Fundación Séneca.

28 Museo Naval de Madrid. Colección Sanz de Barutell. Artículo 6, nº 20.

29 Museo Naval de Madrid. Colección Vargas Ponce. Tomo XXVII, doc. 39.

30 Archivo General de Simancas. G.A., Sec. M. Y T. Leg. 214-46. 
lombarda gruesa de hierro toda de una pieza que pesa 43 quintales con su cepo y afuste ${ }^{31}$ ). Este hábito, que se mantuvo hasta la desaparición de la Escuadra de Galeras al principio del siglo XIX, podemos apuntar que estaba motivado por las siguientes razones:

a) La seguridad que ofrecía el bronce ante el hierro en el lance de que el cañón reventase. En este caso, las piezas de bronce solamente se abrían o rajaban, mientras que las de hierro se rompían en múltiples trozos que volaban como metralla. Veamos algunos ejemplos encontrados en los trabajos de la época:

P.- ¿Cuál es la mejor pieza de artillería, de bronce o de hierro colado?

R.- Mejor mucho es la de bronce, no tan solamente por valer más el metal, como es más segura para tirar, especialmente si está el metal vaciado con liga necesaria ${ }^{32}$.

Toda la artillería se suele hacer de uno de dos géneros de metales; que uno es bronce y el otro hierro. (...) Más, está experimentado que, toda la artillería de hierro de cualquier suerte que sea, sacando los arcabuces, versos y mosquetes, es mala y perjudicial, y podía decir que en las naos, y en el mar no sirve sino de embarazar; y así, suelen decir los navegantes que de ella tiene noticia, que la artillería de hierro mata a la gente de dentro, y espanta a los de afuera, y el mejor metal que hasta ahora se ha hallado para piezas grandes de artillería es el buen cobre, mezclado con buen estaño que sea blando y limpio de otros metales ${ }^{33}$.

De las de hierro solo a mi parecer se deven usar algunas coladas, que teniendo con ellas cuydado aprovechen, y son seguras, todas las demas son mata hombres, y pudiendo aver otras, aun no deverian usarse estas ${ }^{34}$.

b) Para piezas del mismo tipo y calibre, las de bronce tenían alrededor de un $10 \%$ menos de peso que las de hierro. Esta diferencia tenía su importancia en el caso de las piezas principales situadas en la corulla, especialmente en el asunto del cañón de crujía que era la más pesada, por el riesgo de quebranto, en caso de mal tiempo, de la estructura longitudinal del buco de la galera, que tenía una alta relación eslora/manga, al límite de las posibilidades de la construcción naval de la época.

Les canons de bronze avaientl'avantage d'être à calibre égal sensiblemente moins lourds que ceux de fer; ainsi un canon de 36 en fer pesait $3700 \mathrm{~kg}$ et en bronze $3300 \mathrm{~kg}$, mais surtout, le canon de bronze, lorsqu'il éclate ne vole pas en morceaux mais se fend, le canon de fer est consideré comme infinitenent plus dangereux ${ }^{35}$.

c) El hecho de que la artillería de bronce proporcionaba un carácter de distinción o categoría, expresado en el ornato de las piezas, abundante en escudos, motes y distintivos personales (Otro cañon de bronze de 12 palmos de largo y 35 libras de bala, con unas armas reales y del Condestable Mayor de Castilla y de Carrillo de Quesada con letrero que dice. Carrillo de Quesada Capitan General del Artilleria del Reyno de Napoles ${ }^{36}$ ).

En cuanto a las piezas de artillería de bronce sacadas del fondo del mar, hay que destacar que es muy frecuente que estas hayan perdido algún elemento, sobre todo en las recuperadas en fondos poco profundos, en los cuales se hace sentir el efecto de las tempestades. Este fenó-

\footnotetext{
31 Fernández Duro, C. (1972-1973): Armada Española. Madrid, Museo Naval, Tomo I. Págs 348-349.

32 Fernández Duro, C. (1996): Disquisiciones Náuticas. Volumen VI. Madrid, Ministerio de Defensa. Págs. 440-441.

33 Escalante de Mendoza, J. de. (1985): Itinerario de Navegación. Madrid, Museo Naval Madrid. Pág. 44.

34 García de Palacio, D. de. (1587): Instrucion Nauthica, para el buen uso, y regimiento de las Naos, su traça y gobierno conforma à la altura de Mexico. Mexico, Pedro Ocharte. Págs. 121-121 v.

35 Boudriot, J. (1992): L’Artillerie de Mer. París, ANCRE. Pág. 26.

36 Archivo General de Simancas. G.A., Sec. M. y T., Leg. 214-46.
} 
meno es más acusado en las piezas de pequeño calibre y de cámara abierta, siendo las carencias más frecuentes la falta del servidor, recámara, másculo o alcuza; la pérdida del asa de este elemento; la desaparición de la rabiza o rabera; el extravío de las cuñas o calces; la carencia del cepo o braga, de la horquilla o del másculo, cuando este es de hierro, por corrosión. Todo lo apuntado explica el que se hayan producido errores en la interpretación e intervenciones de algunas piezas.

\section{EL ESMERIL BASTARDO}

Los esmeriles son, como ya se ha visto, un tipo de arma «antidotación» que servían para tirar contra blancos determinados. Abundando en el uso del esmeril naval como arma contra blancos concretos (las personas provistas de armas defensivas fuertes o a prueba), veamos algunos textos que nos documentan su uso:

(...) y con el socorro del Marques de Sancta Cruz fueron luego rendidas y presas, y aunque el Marques saco mucha gente herida, y el recibió dos arcabuzazos en una rodela fuerte que le valio ser de a prueva ${ }^{37}$;

(...) le fue a socorrer Don Bernardino de Cardenas a quien tocava hazerlo, y como fue junto de la proa le fue dado un esmerilazo sobre una rodela fuerte que trahia, que aunque no la paso ni le hirio, derribandole entre los remiches murio dello al otro dia por la mañana;

(...) el qual aunque estaba armado a prueba de arcabuz, no se pudo defender de un golpe de esmeril que le dio en el pecho, y no pudiendo pasar el petto fuerte lo hizo caer de espaldas, $y$ del tormento que recibio murio dentro de pocas horas ${ }^{39}$.

Examinemos ahora otro texto que nos traslada el riesgo de no colocarse el espaldar, creyendo que siempre se estará cara al enemigo:

(...) y fue a proa sobre las arrumbadas a dar el puesto a cada uno y proveer de mosqueteros allí. Yo llevéle allá el pecto fuerte y morrión y un par de escofietas de Holanda, y arméle. (...). El capitán estaba junto al árbol mayor, a la parte de proa, que venía de la arrumbada de proveer lo necesario, con su peto, rodela fuerte y todo recado, y llamó al sargento de la compañía, que entonces era Mateo Hidalgo, para que le enviase soldados a proa, que había pocos, y volviéndose hacia la parte del esquife en el cual estaba el sargento, al mismo tiempo que se volvió le dió una bala por el costado siniestro, un dedo del peto, y le salio por la espalda derecha ${ }^{40}$.

Estas armas a prueba de arcabuz eran bastante pesadas, lo que dio lugar a la figura del paje de rodela, que era un muchacho que empezaba el oficio de las armas y, en combate en tierra, se colocaba delante de su capitán, haciendo de parapeto y permitiéndole un mejor control de la situación, con la rodela fuerte y la jineta (especie de lanza corta distintivo del grado de capitán).

37 Bauer Landauer, I. (1921): Don Francisco de Benavides. Cuatralvo de las Galeras de España. Madrid, Jesús López. Pág. 348.

38 Ibidem. Pág. 347.

39 Torres y Aguilera, H. de. (1579): Chronica y Recopilación de varios sucesos de guerra que han acontecido en Italia y partes de Levante y Berberia, desde que el Turco Selim rompio con Venecianos y fue sobre la Isla de Chipre año de M.D.LXX. hasta que se perdio la Goleta y fuerte de Tunez el M.D.LXXIIII. Çaragoça, Juan Soler. Pág. 174.

40 Castro, M. de. (1956): Autobiografías de Soldados. Vida de Miguel de Castro. Edición de José Ma de Cossío. Madrid, Ediciones Atlas. Pág. 514. 
(...) le hacía estar en pie una hora con un morrión fuerte, que pesaba treinta libras, en la cabeza, y con un peto que pesaba otras treinta ${ }^{41}$.

Llegué a Palermo en breve tiempo y luego me recibió por paje de rodela el capitán (...) tocó embarcar la compañía de mi capitán en la galera capitana de César Latorre, de la escuadra de Sicilia; llegamos a Patrás, que está en la Morea, y echamos a gente en tierra, haciendo su escuadrón firme; la gente suelta o volante dieron la entrada con sus escalas por la muralla; aquí sentí las primeras balas, que me zurrearon las orejas, porque estaba delante de mi capitán con $\mathrm{mi}(\mathrm{su})$ rodela y jineta. ${ }^{42}$

Creemos que los textos presentados nos manifiestan una idea clara del uso de las armas defensivas fuertes o a prueba de arcabuz, y de la utilización de los esmeriles de las galeras para anular las armas defensivas de los capitanes y oficiales enemigos. Esta particularidad, unida al hecho de que la pieza que estudiamos representa un modelo de esmeril diseñado para optimizar su empleo contra los oficiales enemigos protegidos con armaduras resistentes, y a la singularidad de la pieza, que nos va a permitir replantearnos la interpretación de otras, pensamos que merecía se le designase de una forma diferenciada. En consecuencia, decidimos bautizar a este esmeril bastardo de 8 onzas de bala con el nombre de matacapitanes.

\section{DESCRIPCIÓN Y DATACIÓN DE LA NUEVA PIEZA}

El esmeril en cuestión es de bronce fundido y de cámara cerrada, conservando, unida a los muñones, una sólida horquilla de hierro con su correspondiente pinzote, motivo por el cual no se ha podido, de momento, determinar su peso. El estado de la pieza es excelente, como puede apreciarse en las figuras 6 y 8 , y conserva en la culata, unida a la lámpara, una pieza cilíndrica hueca, desconocida hasta ahora por nosotros y nunca vista en los museos navales españoles.

La joya o brocal es abocinada y, a partir de su final, la caña se va ensanchando suavemente, formando un tronco de cono, hasta la faja de la culata. Esto indica que el grosor del metal de las paredes del ánima crece en la misma proporción. Entre la joya y los muñones aparece una fina faja, existiendo otra similar antes del fogón. El fogón se halla sobre un pequeño resalte unido a la faja de la culata, y, aunque está en muy buen estado, muestra señales de haber sido utilizado.

En el momento que nos llamó la atención el esmeril, éste conservaba, dentro de su ánima a manera de tapaboca, una rabiza o rabera de madera, que, una vez retirada del interior del objeto encajaba perfectamente en la pieza cilíndrica hueca, anteriormente mencionada, y que a partir de este momento bautizamos como portarrabiza. En la figura 7 hemos realizado varios dibujos donde representamos las distintas partes y detalles del esmeril.

41 Contreras, A. de. (1956): Autobiografías de Soldados. Vida del Capitán Alonso de Contreras. Edición de José Ma de Cossío. Madrid, Ediciones Atlas. Pág. 123.

42 Ibidem. Pág. 79. 


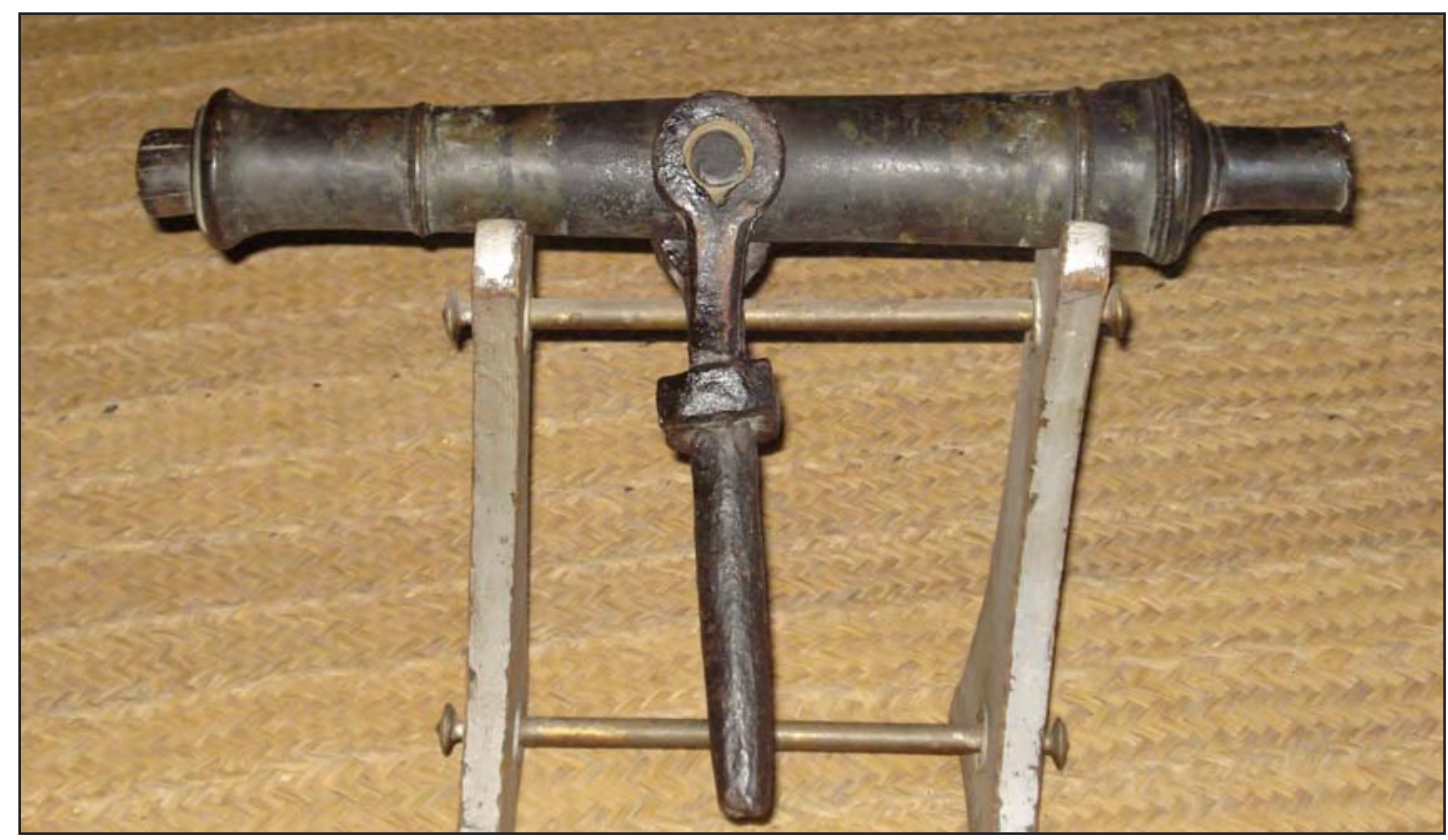

Figura 6. Situación del esmeril Matacapitanes en el lugar de identificación (sala Argos) en el ArchivoMuseo «D. Álvaro de Bazán». Palacio de El Viso del Marqués (Ciudad Real).

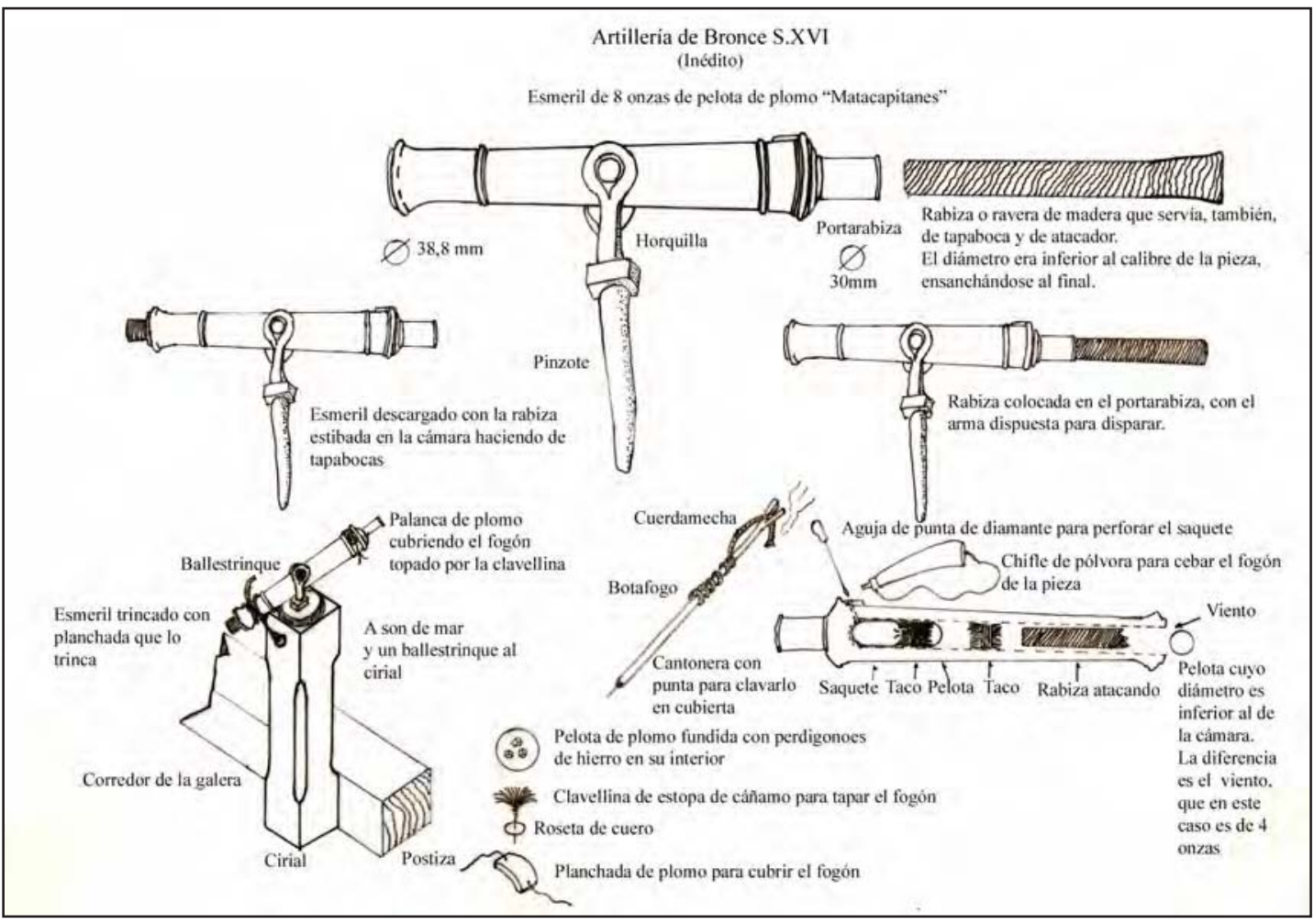

Figura 7. Dibujos que describen las partes y elementos del esmeril bastardo. Fuente: Elaboración propia a partir de la pieza original identificada. 
La pieza, como se verá mas adelante, es de la segunda mitad del siglo XVI.

\begin{tabular}{|l|}
\hline Dimensiones y características de la pieza \\
\hline Pieza de cámara cerrada. \\
\hline Longitud total con la portarrabiza: $56,8 \mathrm{~cm}$. \\
\hline Longitud de la pieza hasta el final de la faja alta de la culata: $48 \mathrm{~cm}$. \\
\hline Longitud de la portarrabiza: $7 \mathrm{~cm}$. \\
\hline Longitud de la rabiza de madera: $31,5 \mathrm{~cm}$. \\
\hline Longitud total de la pieza con la rabiza colocada en el portarrabiza: $82 \mathrm{~cm}$. \\
\hline Longitud del ánima: $46,5 \mathrm{~cm}$. \\
\hline Calibre del ánima: $38,8 \mathrm{~mm}$. \\
\hline Calibres: $13,5$. \\
\hline Espesor de las paredes del ánima: boca $16 \mathrm{~mm}$; medio $17,2 \mathrm{~mm}$; culata $20,4 \mathrm{~mm}$. \\
\hline Diámetro de la bala o pelota: $33,8 \mathrm{~mm}$. \\
\hline Peso de la bala de plomo: 8 onzas $=230 \mathrm{~g}$. \\
\hline Viento de la bala o pelota: 4 onzas $=2,5 \mathrm{~mm}$. \\
\hline
\end{tabular}

Tiene un calibre o calibo de 38,8 mm, que corresponde a 12 onzas de bala de plomo, al cual, restando el aire de 4 onzas, nos da que la pieza tira bala de 8 onzas de plomo, por tanto entra dentro del valor clásico del calibre del esmeril. En este sentido, Diego de Álava, sobre esmeriles, dice: «El esmeril tira de seis hasta doze onças de bala, y su mayor tiro por el punto de nivel es de dozientos y cincuenta passos, y el de mayor caça de novecientos» ${ }^{43}$. Por su parte, Ufano mantiene que «El esmeril que tira dies onças de bala de hierro, y 15. de bala de plomo, con otras quince de polvora Fina, tiene de largo 37 calibres que hazen 7 , pies y medio, y pessa quatro quintales y medio, y alcanza de punteria 315. passos por el nivel del anima 158. por su mayor elevaçion, $1873 »^{44 .}$

Para fijar el límite inferior de la datación de la pieza podemos utilizar como referencia el esmeril de galera de 8 onzas de pelota existente en el Museo Naval de Madrid con el $n^{\circ} 1407$ de catálogo descrito anteriormente en el segundo apartado de este trabajo, que es de 1539.

El límite superior de datación del «matacapitanes» debemos establecerlo al final del siglo XVI, en el cual los esmeriles desaparecen siendo sustituidos por los pedreros, (denominación de una pieza de horquilla que ahora no lanza bolaños o pelotas de piedra, sino balas de hierro de 2, 3 o 4 libras y, principalmente, botes de metralla contra la dotación enemiga, tirando «a bulto»). El tiro contra blancos concretos o «de puntería» se hace con los mosquetes de posta, más pesados que los ordinarios y que tiran balas de plomo de 2 onzas. Así aparece en un documento de 1603:

el enemigo se defende con musqueteria, escopeteria, espadas anchas, medias picas, mosquetes de posta y pedreros cargados con pedazos de hierro y balas de arcabuz $z^{45}$.

Otro texto que reafirma el final del uso de los esmeriles en las galeras es el asiento con el Príncipe de Melfi (Juan Andrea Doria Landi) para la creación de la Escuadra de Galeras de Cerdeña, firmado ya en 1638, en donde figura:

43 Alava y Beamont, D. de. Op. cit. Pág. 160.

44 Ufano, D. de Op. cit. Pág. 21.

45 Font Muñoz, C. (1603): Tratado tocante el Armar y disciplina de las Galeras. Brujas. Manuscrito Fol. 15. En: Library of Congress, Rare Books and Special Collections Division, Washington D.C., The Kraus Collection of Sir Francis Drake, doc. 016. 
que se daran por cada Galera sus 5 piezas de artilleria. Cañon de cruxia dos moyanas y dos pedreros que contados a 60 quintales de bronze a saber 40 para el cañon de cruxia 18 para las dos moyanas y 12 para los dos pedreros...que se le daran ansi mismo por cada Galera 40 mosquetes 20 arcabuces 10 mosquetes de posta y 40 chuzos con sus Hierros ${ }^{46}$.

\section{EL LUGAR DE LOCALIZACIÓN DEL ESMERIL: UNA HIPÓTESIS DE TRABAJO}

El estudio documental que se ha realizado para la identificación y contextualización histórica del esmeril bastardo no deja dudas sobre la datación y utilidad de este, y aunque el lugar de localización de una pieza no significa siempre que pueda considerarse suficiente para determinar el origen de la misma, creemos que en el caso que nos ocupa el edificio donde se ha localizado también se puede tener en cuenta como hipótesis plausible para su datación.

El Palacio de El Viso fue concebido como Casa del Linaje de un noble, Álvaro de Bazán, primer marqués de Santa Cruz, hombre de armas entregado durante toda su vida a la defensa contra los enemigos de la Corona. Ello significa que este edificio fue diseñado como muestra y representación de la ostentación del poder nobiliario y territorial de sus dueños. Por ello, el marqués decidió que fuera el lugar en que se guardara, a través de un buen número de piezas, armas y de pinturas al fresco, la memoria de sus principales y victoriosas actuaciones a lo largo de su vida militar (jornadas del Cabo de Aguer en 1556, del río de Tetuán en 1565, Navarino en 1572, Túnez en 1573, de los Quérquenes en 1576 o Lisboa en 1581). De esta manera, uno de los principales objetivos fue que el edificio albergara y conservara en su interior todos aquellos «trofeos» o piezas más relevantes de estas campañas en que había participado con éxito. La circunstancia de que las piezas de artillería enemigas capturadas pertenecían al rey, que las destinaba a dotar sus galeras (V. doc. nota 55), hace que la pieza «matacapitanes» deba considerarse más un «recuerdo» de su galera que un «trofeo» del enemigo (que solía ser el fanal de las galeras o navíos contrarios, de los cuales se conservan 6 en el Palacio de Santa Cruz en Madrid).

Según López Torrijos, se dotó al palacio de una estancia dedicada a armería, como así consta en la documentación consultada en el archivo familiar del marqués de Santa Cruz, donde se hace una descripción de la situación y utilización de las diferentes estancias del edificio en determinados momentos de su historia. Así, «el salón menor y más próximo a la entrada del palacio sabemos que era la armería en 1646, donde estaban expuestos los arneses, armas, artillería y estandartes propios del marqués de Santa Cruz, más los trofeos ganados en todas sus batallas e incorporados al mayorazgo (armas, rodelas, estandartes, banderas y fanales conseguidos fundamentalmente en las batallas contra el turco y contra portugueses y franceses en las Azores)» ${ }^{47}$.

El marqués, ya viudo, muere en 1588, lo que provoca la dispersión de los hijos, quedando el cuidado del palacio y la continuidad de las obras en dos de sus capitanes de confianza. A pesar de ello, siempre mantuvo la categoría de Casa del Linaje y en él se conservaron durante siglos los documentos que demostraban la nobleza familiar y el origen del mayorazgo ${ }^{48}$. Aunque los hijos varones siguieron la tradición naval, en la época de estos, los esmeriles, como ya explicamos anteriormente, ya no estaban en uso en las galeras.

\footnotetext{
46 Archivo Naval de Cartagena. Documento P-19-may-1638, fol. 7.

47 López Torrijos, R. (2009): Entre España y Génova. El Palacio de Don Álvaro de Bazán en El Viso. Madrid, Ministerio de Defensa. Págs. 175-176.

48 Ibidem. Págs. 212 y 218.
} 
Los avatares por los que ha pasado el edificio han sido muchos y variados a lo largo de los siglos. Citaremos brevemente que, por ejemplo, fueron varias las ruinas declaradas en algunas estancias del inmueble, siendo de las más importantes la producida por el terremoto de Lisboa en 1755. También, el saqueo del edificio realizado por las tropas francesas que estuvieron acantonadas durante la guerra de la Independencia. Ya en el siglo XX, fue escuela durante la Segunda República, pósito y cuartel de la Guardia Civil ${ }^{49}$.

Es probable que la pieza estuviera escondida en algún camaranchón del edificio, oculta, para no sabemos qué destino. A partir de los años cincuenta del pasado siglo, cuando la Armada rehabilitó y acondicionó el edificio, posiblemente debió aparecer la pieza. De esta manera, se explicaría que el esmeril no se encontrara identificado en los espacios del Palacio del Viso dedicados a museo, siendo la única pieza de todas las expuestas en las diversas salas que carecía de leyenda explicativa. La mayoría de las piezas en exposición son de los fondos del Museo Naval de Madrid, y fueron trasladadas por Guillen Tato en los años cincuenta del siglo XX, con el fin de crear un nuevo espacio museístico dependiente de la Armada. Nuestro siguiente paso fue realizar un análisis exhaustivo en la sección de artillería del Museo Naval donde están registradas escrupulosamente todas las piezas, desde su fundación a mediados del siglo XIX, que dependen de dicha institución. Después de varias revisiones e indagaciones en las que participaron personal del Museo Naval, finalizamos con que no existe ningún dato o referencia sobre el esmeril que presentamos. No parece lógico que en el enclave geográfico en que se encuentra el inmueble pueda haber sido trasladado o adquirido hasta nuestros días por persona ajena a los marqueses de Santa Cruz.

\section{CATALOGACIÓN Y ESTUDIO DE LA PIEZA}

Hemos analizado los trabajos sobre artillería de los siglos XVI y comienzos del XVII, y establecido que, si bien pueden servir de guía, no nos parecen definitivos a la hora de la catalogación museística de esta pieza. En ese sentido, estamos de acuerdo con lo expresado por Herrero Fernández-Quesada a la hora de tratar sobre la colección de artillería del Museo del Ejército:

Sin embargo, la nota distintiva es la gran variedad de los materiales, que se fundían arbitrariamente según los criterios personales de cada fundidor. Esta diversidad llevó a tal confusión que, cuando en el mismo Museo de Artillería se intentó exponerlas ordenadamente, terminaron por ceñirse a la clasificación de bocas de fuego que proponía Diego Ufano en su obra que contenía cuatro grandes grupos: artillería menuda, de gran longitud de ánima, de mediana longitud de ánima y artillería corta ${ }^{50}$.

Creemos que resulta más conveniente para la descripción y análisis de una pieza de artillería, si no tenemos una datación exacta de la misma, el analizar las relaciones de artillería de la época, cuando estas tienen los detalles fundamentales de nombre de la boca de fuego, calibre y viento. En cuanto al peso de la pieza este no es determinante, solamente orientativo, debido a las notables diferencias existentes entre fundidores. Veamos algunos documentos que nos aportan una información muy valiosa para la identificación y catalogación de la pieza que presentamos.

\footnotetext{
49 Ibidem. Págs. 218- 220.

50 Herrero Fernández-Quesada, M. D. (1997): «La presencia artillera en el Museo del Ejército. Historia y colecciones». Militaria. Revista de Cultura Militar, 9: 77-101.
} 
Por una parte, el inventario de las municiones, artillería y armas de dos galeazas españolas en el año 1587:

Nápoles, 8 de mayo de 1587. Inventario de las municiones, artillería, armas y otras cosas, consignada a Federico Giudice, patrón de la galeaza capitana asi para el servicio de la dicha galeaza como para llevar de respeto a España:

- Cinco cucharas de hierro para derretir plomo, las dos grandes y tres pequeñas, de peso de 9 rótulos.

-Quatro moldes de bronze con sus mangos de hierro para hazer balas de esmeriles.

-Un esmeril de 6 palmos largo y dos libras de bala, con las armas reales, señalado sobre la cámara, de peso 1 quintal, 87 rótulos... (siguen 3 esmeriles más iguales, con poca variación en el peso).

-Otro esmeril ut supra, de 9 palmos 2/3 de largo, de dos libras de bala, con las armas reales, el peso de quintal 1, rótulos 94... (siguen 14 esmeriles más iguales, con poca variación en el peso).

-Otro esmeril de 6 palmos de largo, libra y media de bala y armas reales, con señal de peso 1 quintal, 97 rótulos.

-Y más cuarenta másculos de bronze para servicio de los dichos veynte esmeriles.

-Un quintal de dados de hierro para las lanternas y para hazer balas de esmeriles.

- Lanternas de leñame para la artilleria, ciento.

-Doscientos pedazos de leñame de quatro palmos y medio para tapar a los másculos.

Galeaza Napolitana:

-20 esmeriles: 8 de 6 1⁄2 palmos de largo y 3 libras de bala, 12 de seis palmos, 4 de ellos de 11 onzas de bala, 3 de diez onzas, 3 de dos libras y dos de una libra ${ }^{51}$.

Por otra, analizada la relación de la artillería de 19 galeras que figura íntegra al final del trabajo (Anexo: Relación de las piezas de artillería que ay en todas las galeras de España y de su peso y Calibo que tienen en el Puerto de Santa Maria en 11 de noviembre de $1590^{52}$ ), podemos decir que:

-De las 19 galeras, 8 no llevan esmeriles.

-Las 11 galeras restantes suman 28 esmeriles.

-El reparto del calibre de los esmeriles es: 1 de a 1 libra (1 libra= 16 onzas); 12 de a 8 onzas; 11 de a 6 onzas; 4 sin especificar el calibre, de los cuales 2 podrían ser de 11 onzas.

-El viento de las pelotas de plomo es: para 1 libra de bala, 6 onzas; para 8 onzas de bala, 4 onzas; para 6 onzas de bala no se especifica pero, siguiendo la regla, deberían ser 3 onzas. Para los posibles de 11 onzas, en los cuales solamente aparece el calibo de 1 libra, el viento sería de 5 onzas.

-No hay indicación de longitud, ni de si los esmeriles son de cámara cerrada o de cámara abierta con másculo, excepto en dos casos que aparecen los másculos, pero lo usual era lo segundo, como aparece en las notas 28 y 51.

-El resto de las piezas «antidotación» lo forman morteretes, cañones pedreros y busacos en un total de 27 bocas de fuego.

51 Archivo General de Simancas. G.A., Secc. M. y T., Leg. 214-46.

52 Museo Naval de Madrid. Colección Sanz de Barutell, Art. 4, nº 1070, 
De todo ello podemos inferir dos conclusiones:

a) El calibre de los esmeriles navales, en el último cuarto del siglo XVI, oscilaba entre 6 onzas y 3 libras (48 onzas). Este es mucho mayor al limite superior (15 onzas) fijado por Ufano, demostrándose la conveniencia de aplicar los datos de la documentación coetánea para la clasificación y catalogación de las piezas de artillería de este siglo.

b) Las balas o pelotas eran de plomo, como indican todos los autores, que se fundían a bordo, con uno o varios dados de hierro en su interior para dar consistencia a la pelota. La observación de Ufano sobre que el esmeril puede disparar 10 onzas de bala de hierro o quince de plomo hay que tormarla con cuidado: $1^{\circ}$ porque la equivalencia no anda muy fina entre pelotas del mismo diámetro, de media a una onza de diferencia, según la densidad que apliquemos al hierro colado; $2^{\circ}$ porque la carga de pólvora que indica corresponde exclusivamente al peso de la pelota de plomo; $3^{\circ}$ porque, si se emplearan balas de hierro, la energía cinética de la bala sería casi la mitad que si se empleasen pelotas de plomo.

En cuanto a la utilidad y a las características de las piezas empleadas en tierra y en la mar, podemos apuntar que en tierra parece que el esmeril no era una pieza muy abundante. De hecho, aparece poco en el excelente trabajo de Arántegui. Una de las pocas veces que se encuentra es está:

En la plaza de San Sebastian existían en el mes de abril de 1547 las piezas que siguen: (...). Un esmeril ochavado que tira pelotas de media libra con otra tanta polvora tiene por devisa una flor de lis en el fogon y de este a la boca 38 pelotas $^{53}$.

(...) en la misma época en Fuenterrabía (...). Un esmeril ochavado que tira pelota de 4 onzas con otra tanto polvora tiene por devisa una flor de lis en el fogon y de largo 24 pelotas $^{54}$.

Veamos otro texto, de la mitad del siglo XVI, sobre el uso de los esmeriles:

Saliendo yo del cuerpo de guardia para ir a mi trinchea, que era manco de media milla, vi que de la muralla asestaban los esmeriles para los que estábamos en campaña. Yo calé mi serpentina y llévele al bonbardero el Botafogo de la mano ${ }^{55}$.

Creemos que está claro el uso de esta pieza, que resultaba una especie de arcabuz potente, tanto en tierra como en la mar; y que se empleaba contra individuos concretos, zapadores, mineros, oficiales, protegidos por defensas ligeras, tablachinas, o petos, morriones o rodelas, fuertes o a prueba, capaces de detener una bala de arcabuz. En la mar esta boca de fuego formaba parte de la artillería «antidotación», y su empleo solamente se justificaba contra blancos individuales, pues, para tirar a bulto, resultaba más eficaz dar una ruciada (sic) de arcabucería o emplear los pedreros, morteretes o busacos, con los bolaños y linternas, como anteriormente hemos explicado.

Para una mejor compresión de las características de los esmeriles terrestres y navales, hemos confeccionado la tabla 1, tomando como base los datos que aparecen en los documentos citados en las notas 54, 56 y 57. Desafortunadamente, no se han podido utilizar los datos de la nota 55 al no figurar la longitud de las piezas:

53 Arántegui y Sanz, J. Op. cit. Págs. 350-352.

4 Ibidem. Págs. 352-354.

55 Anónimo (2000). Viaje de Turquía. Edición de Marie-Sol Ortola. España, Editorial Castalia. Pág. 273. 
Tabla 1. Comparación de las características de esmeriles terrestres y navales. Fuente: elaboración propia a partir de los documentos de las notas 54, 56 y 57.

\begin{tabular}{|l|c|c|}
\hline \multicolumn{1}{|c|}{ Esmeriles } & Diámetro de la bala & $\mathrm{N}^{\mathrm{o}}$ de balas que caben en el ánima \\
\hline Esmeriles terrestres & & \\
Esmeril terrestre 1 & Calibre 8 onzas & Calibres 38 pelotas \\
Esmeril terrestre 2 & Calibre 4 onzas & Calibres 24 pelotas \\
Esmeriles navales & & \\
Esmeril naval 1 & Calibre 10 onzas & Calibres 33 pelotas \\
Esmeril naval 2 & Calibre 11 onzas & Calibres 32 pelotas \\
Esmeril naval 3 & Calibre 1 libra & Calibres 28 pelotas \\
Esmeril naval 4 & Calibre 2 libras & Calibres 36 pelotas \\
Esmeril naval 5 & Calibre 2 libras & Calibres 24 pelotas \\
Esmeril naval 6 & Calibre 2 libras & Calibres 22 pelotas \\
Esmeril naval 7 & Calibre 3 libras & Calibres 21 pelotas \\
\hline
\end{tabular}

De la información de la tabla, a la que sólo hay que dar valor indicativo, no parece desprenderse que existan diferencias entre los esmeriles empleados en tierra y los utilizados en la mar. Por otro lado, conviene destacar que, conforme a los datos del documento de la nota 39, al menos, el 82\% de los esmeriles de las galeras tiraban balas de 8 ó 6 onzas, con un reparto al $50 \%$ entre los dos calibres (entendido aquí como peso de bala).

De lo expuesto, podemos llegar a dos conclusiones con respecto a la pieza que presentamos: el calibre está dentro del marco de los más utilizados en los esmeriles de galeras, y los calibres del arma están bastante por debajo de los usuales del género al que pertenece, por lo que hay que clasificarlo como esmeril bastardo.

Pasemos ahora a comentar algunas de las peculiaridades de esta pieza en relación con las modificaciones que presenta respecto a los parámetros de los tres géneros, culebrinas, cañones y pedreros, en que se dividían:

$1^{\circ}$ Dado el calibre de la bala, 8 onzas de plomo, si fuese de hierro serían 5 onzas, estamos, como ya hemos dicho, en el género de las culebrinas y en sus representantes menores, esmeriles y mosquetes de posta. Los cañones y pedreros no tenían piezas de calibre tan bajo.

$2^{\circ}$ Los calibres del arma rebasan por abajo el límite establecido en su género para las bocas de fuego bastardas: «La media culebrina bastarda no puede tener más de 25 calibres y la mas bastarda no puede tener menos de 15 a 16 calibres» ${ }^{56}$. Estamos pues ante un esmeril de calibres, o dicho de otra forma, de longitud de ánima, más corta del límite del género.

$3^{\circ}$ La pieza, a diferencia de lo usual que era cámara abierta con másculo, es de cámara cerrada. Esto contribuye también a acortar la longitud del arma.

56 Serneira de Aguilar, M. Op. cit. Fol. 21. 
$4^{\text {o }}$ No tiene rabiza de firme, pieza de bronce o de hierro, según los casos, que servía para manejar y apuntar la boca de fuego. En su lugar lleva en la culata un corto cilindro hueco de bronce, portarrabizas, donde se introduce la rabiza de madera.

$5^{\circ}$ La conjunción de las características de los puntos $2^{\circ}, 3^{\circ}$ y $4^{\circ}$ producen un arma muy ligera y corta, y, por tanto, muy manejable en comparación con los esmeriles «clásicos». Esta circunstancia era interesante si tenemos en cuenta la estrechez del corredor de la galera (un metro aproximadamente), pasillo que corría de popa a proa, en ambas bandas, adosado a la postiza, y lugar donde se solían colocar los esmeriles sobre ciriales (columnas cortas de madera).

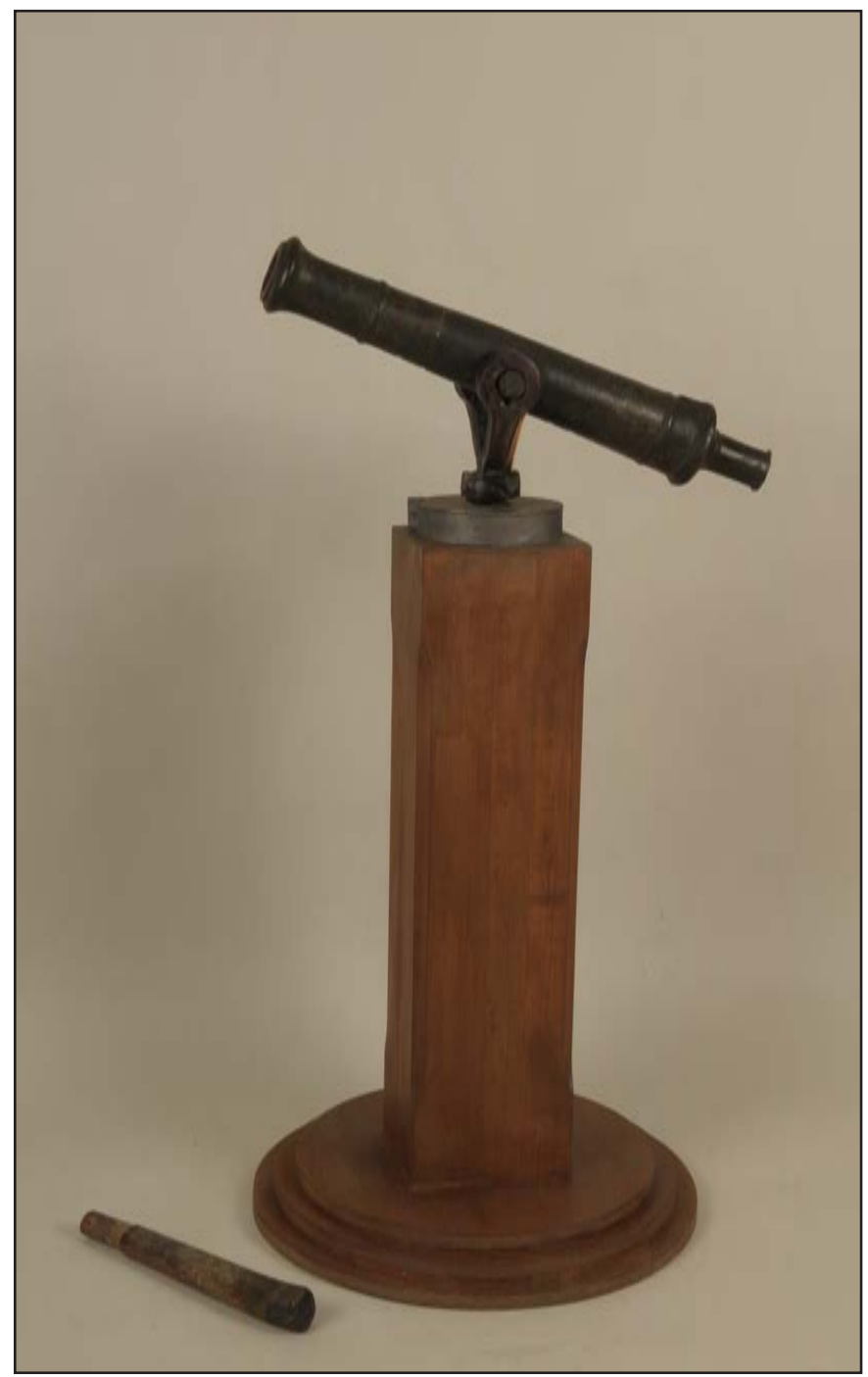

Figura 8. Esmeril Matacapitanes colocado sobre una reproducción de un cirial, tal y como iba en el costado de la galera. La rabiza original aparece en la parte inferior de la imagen. Museo Naval de Madrid. 
$6^{\circ}$ A todo lo anterior hay que añadir que el carácter portátil de la rabiza y su diseño calculado para servir de atacador a la pieza, y para alojarse, en posición de reposo, en el interior del ánima, sirviendo de tapabocas, facilitaba la utilización de la boca de fuego.

\section{CONCLUSIONES}

El diseño del esmeril Matacapitanes supuso un notable avance en los esmeriles de la época, especialmente para los utilizados en las galeras. Esta pieza, cuyo período de utilización es la segunda mitad del siglo XVI, supone un notable avance con respecto al esmeril de la primera mitad del siglo (figs. 1, 2, 3 y 4). El esmeril de 1539, del género de las culebrinas, es muy largo para utilizarlo en el corredor, pasillo que corría por ambas bandas de la galera, por lo cual se montaba en la parte de proa de la corulla, sobre unos postes cortos, los maimones. Esta colocación proel limitaba su uso al momento del abordaje y proporcionaba un campo de tiro limitado a la zona de la proa enemiga. Haciéndolo bastardo, es decir, acortando su longitud, que al ser el disparo cercano ya no es necesario que fuera de tantos calibres, y fabricándolo con la cámara cerrada, sin másculo, se podía montar en el corredor de la galera, en número de 5/6 por banda, utilizándolo para tiro a puntería contra los oficiales enemigos provistos de arneses a prueba de balas de arcabuz. A finales del siglo XVI se sustituyó el esmeril por el pedrero, un arma parecida al esmeril bastardo pero de mayor calibre, que lanzaba botes de metralla contra la gente enemiga.

Por otro lado, el uso de la rabiza portátil, con un sistema parecido que hasta ahora no había sido interpretado, aparece en otros esmeriles del mismo siglo, por lo que será necesario reinterpretar de nuevo varías piezas, empeño en el que nos centraremos en un próximo trabajo.

\section{BIBLIOGRAFÍA}

Alava y Beamont, D. (1590): El perfecto capitan instruido a la disciplina militar y nueva ciencia de la Artillería. Madrid, Pedro Madrigal.

Arántegui y Sanz, J. (1891): Apuntes históricos sobre la Artillería Española en la primera mitad del siglo XVI. Madrid, Imprenta del Cuerpo de Artillería.

Arnold, T. (2001): The Renaissance at War. Londres, Cassell.

Boudriot, J. (1992): L’Artillerie de Mer. París, ANCRE.

Castiñeiras, P. (1958): «La artillería naval en la época del Emperador». Revista General de Marina. Octubre: 440-447.

Chaves, A. de (1983): Espejo de Navegantes. Madrid, Museo Naval Madrid.

Collado de Lebrija, L. (1592): Plática manual de artillería. Milán, Pablo Gotardo Poncio.

Crescentio Romano, B. (1602): Nautica Mediterranea. Roma, Bartolomeo Bonfadino.

Escalante de Mendoza, J. de (1985): Itinerario de Navegación. Madrid, Museo Naval Madrid.

Fennis, J. (1995): Tresor du langage des galères. 3 tomos. Tübingen, Max Niemeyer Verlag.

Fernández Duro, C. (1996): Disquisiciones Náuticas. Volúmenes I y VI. Madrid, Ministerio de Defensa.

Firrufino, J. C. (1626): Platica manual y breve compendio de artillería. Madrid, viuda de Alonso Martín.

Fondevila Silva, P. (2006): «Iconografía y documentación náutica española de los siglos XVI al XVIII. Su aplicación a la identificación de buques, tipos de embarcaciones y de aparejos». En: Sánchez Baena, J. J. y Provencio, L. (eds.): El Mediterráneo y América. Murcia, Editora Regional, p. 153-164.

Fondevila Silva, P. (2010): «Tipología de las galeras españolas del siglo XVI». Revista de Historia Naval, 110: 25-52.

Fondevila Silva, P. (2011): Diccionario Español de la Lengua Franca Marinera Mediterránea. Murcia, Fundación Séneca. 
Fondevila Silva, P. y Sánchez Baena, J. J. (2010): «Las galeras de la monarquía hispánica: elemento fundamental del poder naval durante el siglo XVI». En Alvar Ezquerra, M. y Ruiz Rodríguez, J. I. (eds.): Túnez 1535. Madrid, CSIC: 89-119.

García de Palacio, D. de (1587): Instrucion Nauthica, para el buen uso, y regimiento de las Naos, su traça y govierno conforme a la altura de Mexico. Mexico, Pedro Ocharte.

García-Parreño y Kaden, J. (1982): Las armas navales españolas. España, Empresa Nacional Bazán de Construcciones Navales Militares, S.A.

Guglielmotti, A. (1889): Vocabulario Marino e Militare. Roma, Voghera Carlo.

Lechuga, C. (1611): Discurso del Capitán Cristóbal Lechuga, en que trata de la artillería y de todo lo necesario a ella, con un tratado de fortificación y otros advertimientos dirigido al Rey Nuestro Señor. Milán Palacio Real y Ducal, Marco Tulio Malatesta.

López Martín, F. J. (1999): «Un cañón de Cristóbal Frisleva en el Museo Naval de Madrid». Gladius, XIX: 197-220.

López Torrijos, R (2009): Entre España y Génova. El Palacio de Don Álvaro de Bazán en El Viso. Madrid, Ministerio de Defensa.

Martin, C. y Parker, J. (1999): The Spanish Armada. 2nd ed. Manchester, Mandolin.

Morin, M. (2002): La battaglia di Lepanto: alcuni aspetti della tecnologia navale Veneziana. Meditando sull'evento di Lepanto. Odiene interpretazione e memori. Venezia, Instituto di Studi Militari Marittimi.

Muñoz, A. (1612): Instrucciones para el uso de la artilleria en el mar. Sevilla, Tomé de Dios.

Olesa Muñido, F. F. (1971): La Galera en la Navegación y el Combate. 2 tomos. Madrid, Junta Ejecutiva del IV Centenario de la Batalla de Lepanto.

Ríos, V. de los (1767): Discurso sobre los Ilustres Autores e Inventores de Artillería. Madrid, Joachin Ibarra.

Salas, R. de (1831): Memorial Histórico de la Artillería Española. Madrid, sucesores de García.

Sánchez Baena, J. J. (2010): «La necesidad y el empleo de galeras en el mar Caribe en la segunda mitad del siglo XVI». Revista de Historia Naval, 110: 75-96.

Ufano, D. (1613): Tratado de la Artilleria y uso della Platicado por el capitan diego ufano en las guerras de Flandes. Bruselas, Juan Monarte.

Vicente Maroto, M. I. (2002-2003): «Las escuelas de artillería en los siglos XVI y XVII». Quaderns d'historia de l'enginyeria. Volum V. Disponible en http://upcommons.upc.edu/revistes/ bitstream/2099/734/1/escuelas_artilleria.pdf.

Vigón, J. (1947): Historia de la Artillería española. Madrid, CSIC.

\section{ANEXO}

Relación de las piezas de artillería que ay en todas las galeras de España y de su peso y Calibo que tienen en el Puerto de Santa Maria en 11 de noviembre de 1590 (Museo Naval de Madrid. Colección Sanz de Barutell, artículo 4, No 1070).

\section{Capitana}

Un cañon de cruxia de Malaga de peso de cuarenta y quatro quintales y dos libras, tira de vala veinte y cinco libras, tiene veinte y seis de calibo.

Dos sacres fundición de Napoles de pesso el uno, ocho quintales y treinta y ocho rotulos peso de allí, y el otro de pesode ocho quintales y cincuenta y seis rotulos y de calibo tienen cada uno seis libras tiran cinco de vala.

Dos medios cañones pedreros de la misma fundicion pesa cada uno seis quintales y treinta y ocho rotulos aunque el uno tiene veinte libras menos tiene de calibo ocho libras.

Quatro esmeriles el uno pesa tres quintales y cinquenta libras peso de Castilla, tira de vala una libra de calibo libra y media; el otro fundición de Napoles pesa dos quintales y medio tira de vala ocho onzas tiene de calibo doze: Otro pesa quintal y medio tira de vala ocho onzas y doze de calibo: otro del propio peso y calibo 


\section{Patrona}

Un medio cañon que sirve en Cruxia fundición de Malaga de don Frances de Alava pesa beinte y dos quintales y veinte libras tira de vala diez y seis libras tiene de calibo18 libras.

Dos medios sacres fundición de Alemania pesa cada uno de onze a doze quintales tira de vala cada uno cinco libras y media tiene de calibo seis y media.

Dos pedreros pesan de seis a siete quintales cada uno tiran de vala de 7 a 8 libras tienen 7 de calibo [debe ser un error porque lo correcto sería 9].

\section{Peregrina}

Un cañon de Cruxia fundición de Malaga pesa Cinquenta y dos quintales y noventa y ocho libras tira de vala treinta libras tiene 32 de calibo

Un sacre fundición de Malaga pesa diez y seis quintales y treinta y ocho libras tira de vala seis libras y media tiene de calibo siete.

Un falconete fundición de la misma Malaga pesa de cinco a seis quintales tira de dos libras y media de vala tiene tres de calibo.

Otro falconete de la misma fundicion peso y calibo.

Un morterete pedrero pesa de tres quintales y medio a quatro tira de vala de seis o siete libras.

\section{Santiago}

Un medio cañon de Cruxia de la fundicion del don Frances de Alava pesa treinta quintales setenta libras tira de vala 16 libras y de calibo tiene 17.

Dos Moyanas fundición de Napoles pesa la una quatro quintales y treinta y ocho rotulos peso de allí. La otra pesa cinco quintales y 55 rotulos tiran de vala tres y media la una y quatrolibras y media la otra de calibo a 4 y cinco.

Un medio cañon pedrero fundición de Berberia de diez a onze quintales de peso tira de vala cinco libras de calibo tiene seis.

Otro quarto de cañon pedrero fundición de florencia pesa quintales y veinte libras tira de tres libras y media a quatro de vala.

\section{S. Francisco}

Medio Cañon de Crugia fundición de Malaga de la de don Frances de Alava pesa 29 quintales y 17 libras tira diez y seis de vala, tiene de calibo 17.

Dos medios sacres fundición Venecia de peso de seis a siete quintales cada uno tiran de vala quatro libras y media.

Dos medios falconetes fundición de flandes pesa cada uno poco mas o menos de cinco a seis quintales, tiran de vala dos libras.

\section{Sta. Catalina}

Medio cañon de Cruxia fundicion de Malaga pesa 29 quintales y 29 libras y media tira de vala 16 libras, tiene de calibo 17.

Dos pedreros que pesa cada uno de seis a siete quintales que tiran ocho libras de vala tienen nueve de calibo.

Quatro esmeriles pesa cada uno noventa y ocho rotulos poco mas o menos fundicion de Napoles tiran a ocho onzas de vala.

\section{Soberana}

Medio cañpon de Cruxia fundición de Malaga pesa 30 quintales y quatro libras tira de vala 16 tiene de calibo 17.

Dos medios sacres de la misma fundición pesan de diez a onze quintales cada uno, tiran de vala quatro libras, de calibo tienen a cinco.

Un falconete de la misma que pesa cinco quintales tira quatro libras de vala.

Otro falconete fundición turquesca tira una libra de vala.

Dos esmeriles fundición de florencia pesan entrambos quatro quintales tiran de vala 6 onzas. 


\section{Forteza}

Un cañon de Cruxia aculebrinado fundición de Sevilla pesa 40 quintales y 20 libras tira de vala 14 libras y tiene 16 de calibo.

Dos falconetes fundición de Malaga quel uno pesa 6 quintales y 35 libras tira de vala libra y media y tiene dos de Calibo.

El otro de la misma fundición de Malaga quel uno pesa 5 quintales y 34 libras tira lo mismo y del mismo calibo.

Dos quartos cañones pedreros que cada uno pesa de seis quintales a seis y medio tiran de vala a ocho libras.

Dos Esmeriles pesan quintal y medio cada uno tiran seis onzas de vala.

\section{Fortuna}

Un cañon de Cruxia de la fundicion de Genova tiene 38 quintales y 70 rotulos peso de alli tira 16 libras de vala 17 de calibo.

Dos sacres el uno fundicion de Sevilla y el otro de Napoles que pesa cada uno ocho quintales y treinta y ocho rotulos, tiran a quatro libras y quatro y media de vala tienen cinco de calibo.

Dos falconetes fundición de Malaga que pesaran de quatro quintales y medio a cinco que tiran dos libras de vala cada uno tienen a dos y medio de calibo.

Dos Busacos fundicion de Sevilla que pesaran a dos quintales y medio cada uno son pedreros tienen de Calibo a 8 libras.

Dos Esmeriles fundición de Napoles el uno pesa un quintal y dos rotulos y el otro un quintal y un rotulo tienen de calibo cada uno una libra.

\section{Palma}

Un cañon de Cruxia fundicion de Genova pesa 44 quintales y tira de vala 27 libras tiene de Calibo 29.

Un sacre fundición de roma pesa 8 quintales y 80 libras tira de vala 7 libras y media tiene nueve de Calibo.

Dos medios sacres de fundición de Genova, el uno pesa 9 quintales y 20 libras peso de allí tira de vala 4 libras y media tiene de Calibo 5.

El otro de fundición Turquesca pesa cinco quintales y cincuenta rotulos tira 3 libras y media 4 de Calibo.

Quatro Esmeriles de diferente fundicion que pesaran a quintal cada uno tiran a seis y a ocho onzas de vala de plomo.

Otro medio sacre fundicion de Sicilia pesa 4 quintales y 50 libras peso de alli tira quatro libras.

\section{Quimera}

Un cañon de Crugia de la fundicion de Francia que pesa 3960 libras peso de alli tira de vala 24 libras tiene de Calibo 26.

Dos medios sacres de la fundicion de Malaga que pesa cada una de seis a siete quintales. tira el uno tres libras y medio y el otro quatro y media tienen de Calibo el uno cinco libras y el otro quatro.

Dos falconetes de la misma fundición que pesaran de quatro quintales y medio a cinco, tiran de vala cada uno dos libras.

Dos Busacos fundicion de Sicilia pesan de quatro a cinco quintales cada uno tiran de vala a 8 libras de piedra.

\section{Serena}

Un Cañon de Crugia que pesa 44 quintales tira de vala 25 libras tiene de Calibo 27.

Dos sacres fundición de Genova que pesa cada uno a 6 quintales y 20 rotulos tiran de vala a cinco libras cada uno de Calibo 6.

Dos falconetes que pesan a cinco quintales cada uno tiran de vala a dos libras cada uno.

Dos Busacos que pesaran cada uno de Cinco quintales a seis tiran de vala a ocho libras cada uno, de piedra.

Dos Esmeriles pesaran cimal de quintal cada uno tiran valas de plomo de 6 onzas.

\section{Saxitaria}

Un Cañon de Crugia que pesa 44 quintales y 6 libras tira de Vala 23 libras tienen de Calibo 25. 
Dos sacres que pesaran de onze a doze quintales cada uno tiran de valas tres libras y media.

Dos Busacos tiran vala de piedra de seis a siete libras pesaran de quatro quintales cada uno.

\section{Florida}

Un medio Cañon de Cruxia de la fundicion de don Frances de Alava pesa 28 quintales y 27 libras tira 16 de vala tiene de Calibo 18.

Una moyana fundicion de Francia pesara de 8 a nuebe quintales tira de vala tres libras y media.

Otra moyana que pesa 12 quintales y 32 libras tira de bala quatro libras y media.

Un falconete fundición de Malaga pesa cinco quintales y treinta libras tira de vala 2.

Dos busacos fundición de Napoles que pesaran de cinco a seis quintales cada uno tira de vala a 8 libras.

Dos esmeriles que pesaran poco mas de un quintal cada uno, tiran vala de plomo seis onzas.

\section{Sta. Anna}

Un Cañon de Cruxia fundicion de Malaga pesa 28 quintales y 28 libras tira de vala 16 calibo 17.

Un sacre de la misma fundicion que pesa 11 quintales y 55 libras tira de bala 4 libras.

Tres falconetes de la misma fundicipn que pesan a cinco quintales cada uno tiran de vala dos libras.

Dos busacos que pesaran a tres quintales cada uno tiran de vala a tres libras y media.

\section{Vitoria}

Medio Cañon de la fundicion de Malaga pesa 30 quintales y 50 libras tira de vala 16.

Un medio sacre fundicion de Flandes que pesara 12 quintales tira de vala 4 libras.

Otro medio sacre de la fundicion misma pesara 10 quintales tira de vala tres libras.

Un busaco de la fundicion de Sicilia pesara tres quintales tira de vala de seis a siete libras.

Otro busaco de la fundicion de Napoles tira de vala lo mismo y es del mismo peso.

Dos esmeriles que pesara cada uno poco mas de un quintal tiran de seis onzas a ocho de vala de plomo.

\section{Leona}

Un medio Cañon de Cruxia que pesa 29 quintales y 30 libras tira de vala 17.

Dos moyanas fundición de Mala(ga) que pesan a quintales tiran de vala a cinco libras.

Un falconete fundición de Saboya que pesaran cinco quintales a cinco y medio quintales tira de libra y medio de vala.

Dos busacos pesaran a tres quintales cada uno tiran a 6 libras de vala de piedra.

Un falconete fundicion de Malaga que pesara Cinco quintales tira libra y media de vala.

Dos Esmeriles fundicion de Mala(ga) que pesaran cinco quintales entrambos tiran a 8 onzas de plomo de vala.

\section{Granada}

Un medio Cañon que pesa 29 quintales y 60 libras de la fundición de don Frances de Alava tira de vala 16 libras.

Dos sacres fundicion de Napoles el uno pesa ocho quintales y 60 rotulos peso de alli tira de vala cinco libras, pesa el otro 8 quintales y 48 rotulos y tira de vala lo mismo.

Dos Esmeriles con sus Camaras que pesan entrambos tres quintales.

\section{Sta. Barbara}

Un Cañon de Cruxia fundicion de Genova pesa de 21 a 22 quintales tira de vala 13 libras.

Dos medios sacres fundicion de Venecia pesan a 12 quintales cada uno tiran de vala quatro libras y a tres y media.

Un medio sacre fundicion de Malaga del mismo peso y tira lo mismo.

Recibido: 27/10/2010

Aceptado: 18/02/2011 